\title{
Vertical profiling of Saharan dust with Raman lidars and airborne HSRL in southern Morocco during SAMUM
}

\author{
By MATTHIAS TESCHE ${ }^{1 *}$, ALBERT ANSMANN ${ }^{1}$, DETLEF MÜLLER ${ }^{1}$, DIETRICH \\ ALTHAUSEN ${ }^{1}$, INA MATTIS ${ }^{1}$, BIRGIT HEESE ${ }^{1}$, VOLKER FREUDENTHALER ${ }^{2}$, MATTHIAS \\ W IEGNER ${ }^{2}$, MICHAEL ESSELB ORN ${ }^{3}$, GIANLUCA PIS A N ${ }^{4}$ and PETER KNIPPERTZ ${ }^{5}$, \\ ${ }^{1}$ Leibniz Institute for Tropospheric Research, Permoserstr. 15, 04318 Leipzig, Germany; ${ }^{2}$ Meteorological Institute, \\ Ludwig-Maximilians-Universität, Theresienstr. 37, 80333 Munich, Germany; ${ }^{3}$ Institute of Atmospheric Physics, \\ German Aerospace Center (DLR), Oberpfaffenhofen, 82234 Wessling, Germany; ${ }^{4}$ CNISM-Naples, and Physics \\ Department, University Federico II Naples, Via Cinthia, I-80126 Naples, Italy; ${ }^{5}$ Institute for Atmospheric Physics, \\ Johannes Gutenberg University, Becherweg 21, 55099 Mainz, Germany
}

(Manuscript received 31 December 2007, in final form 11 July 2008)

\begin{abstract}
Three ground-based Raman lidars and an airborne high-spectral-resolution lidar (HSRL) were operated during SAMUM 2006 in southern Morocco to measure height profiles of the volume extinction coefficient, the extinction-to-backscatter ratio and the depolarization ratio of dust particles in the Saharan dust layer at several wavelengths. Aerosol Robotic Network (AERONET) Sun photometer observations and radiosoundings of meteorological parameters complemented the ground-based activities at the SAMUM station of Ouarzazate. Four case studies are presented. Two case studies deal with the comparison of observations of the three ground-based lidars during a heavy dust outbreak and of the ground-based lidars with the airborne lidar. Two further cases show profile observations during satellite overpasses on 19 May and 4 June 2006. The height resolved statistical analysis reveals that the dust layer top typically reaches 4-6 km height above sea level (a.s.l.), sometimes even $7 \mathrm{~km}$ a.s.1.. Usually, a vertically inhomogeneous dust plume with internal dust layers was observed in the morning before the evolution of the boundary layer started. The Saharan dust layer was well mixed in the early evening. The $500 \mathrm{~nm}$ dust optical depth ranged from $0.2-0.8$ at the field site south of the High Atlas mountains, Ångström exponents derived from photometer and lidar data were between $0-0.4$. The volume extinction coefficients $(355,532 \mathrm{~nm})$ varied from $30-300 \mathrm{Mm}^{-1}$ with a mean value of $100 \mathrm{Mm}^{-1}$ in the lowest $4 \mathrm{~km}$ a.s.1.. On average, extinction-to-backscatter ratios of $53-55 \mathrm{sr}( \pm 7-13 \mathrm{sr})$ were obtained at 355,532 and $1064 \mathrm{~nm}$.
\end{abstract}

\section{Introduction}

Vertically resolved observations of dust in or very close to a desert dust source are required for an improved modelling of the atmospheric dust transport from the source to remote areas and to improve the parametrization of the interaction of mineral dust with solar and terrestrial radiation in radiative transfer models. The optical properties of pure desert dust at an almost negligible level of maritime and anthropogenic particles as needed for such a parametrization are, however, not easy to obtain. In this respect, the Saharan mineral dust experiment (SAMUM, Heintzenberg, 2008) was unique. The two SAMUM field sites were close to

\footnotetext{
${ }^{*}$ Corresponding author. e-mail: tesche@tropos.de DOI: 10.1111/j.1600-0889.2008.00390.x
}

the Sahara in an outflow regime of Saharan dust, so that most of the experiments could be conducted in pure dust.

Three polarization-Raman lidars were deployed at the airport of Ouarzazate $\left(30.9^{\circ} \mathrm{N}, 6.9^{\circ} \mathrm{W}, 1133 \mathrm{~m}\right.$ height above sea level, a.s.l.) in the foothills of the High Atlas mountains in MayJune 2006. A high-spectral-resolution lidar (HSRL) aboard the FALCON aircraft of the German Aerospace Center (DLR, Esselborn et al., 2008) operated four times over the Ouarzazate area to complement the ground-based lidar observations. These advanced lidars allowed a direct measurement of vertical profiles of the volume extinction coefficient and the corresponding extinction-to-backscatter ratio (lidar ratio) of the non-spherical dust particles at ambient conditions. It should be mentioned that many Raman lidars measure desert dust plumes in the framework of the European Aerosol Research Lidar Network (EARLINET) project (Ansmann et al., 2003; Müller et al., 2008; Papayannis 
et al., 2008). However, the frequent observations in southern Europe are performed in aged dust, often mixed with maritime particles and urban haze (Balis et al., 2004; Mona et al., 2006; Papayannis et al., 2008). The situation is similar when dust layers are monitored in eastern Asia (Sakai et al., 2002; Murayama et al., 2003; Chen et al., 2007; Tesche et al., 2007).

The lidar ratio of desert dust particles is valuable for two reasons. The lidar-derived volume backscatter coefficient (scattering at $180^{\circ}$ ) of the dust particles and thus the lidar ratio is rather sensitive to the shape of the non-spherical dust particles (Mishchenko et al., 1997; Barnaba and Gobbi, 2001; Liu et al., 2002; Mattis et al., 2002c) and additionally depends on their chemical composition (index of refraction) and microphysical properties (size distribution). Therefore, the lidar ratio is an important parameter to test and improve model approaches that have been developed to compute the optical properties of dust from the basic chemical and physical properties (Dubovik et al., 2006; Otto et al., 2008; Wiegner et al., 2008). In turn, these models may be used to retrieve microphysical parameters such as the volume size distribution from spectrally resolved Sun photometer measurements (Dubovik et al., 2006). Measured dust lidar ratios are also needed to check the reliability of vertical profiles of the particle extinction coefficient and the dust optical depth derived from observations with standard backscatter lidars, for example, with spaceborne lidars (Ansmann, 2006) such as the cloud-aerosol lidar and infrared pathfinder satellite observations (CALIPSO) lidar (Winker et al., 2007; Liu et al., 2008).

Another important point of SAMUM is that the total or volume depolarization ratio, that is, the ratio of the cross-polarized to the parallel-polarized backscattered radiation was measured, for the first time, simultaneously at four wavelengths (355, 532, 710 and $1064 \mathrm{~nm}$, Freudenthaler et al., 2008) with the SAMUM lidars. The retrieved particle depolarization ratio is a fundamental quantity in characterizing dust particles and for testing and improving models describing dust optical properties.

It is well accepted to investigate the radiative impact of aerosols by means of so-called column closure experiments (Russel and Heintzenberg, 2000). In these experiments, the relationship between the microphysical and chemical properties of aerosols and the resulting optical and radiative effects is studied by combining observations and aerosol modelling. The concept of closure experiments has successfully been applied during several field studies, for example, the Lindenberg Aerosol Characterization Experiment 1998 (LACE 98, Ansmann et al., 2002a), which focussed on the radiative effects of central European haze. Most groups of the SAMUM consortium were involved in the LACE 98 activities.

In the first step of the SAMUM column closure studies, ground-based and aircraft lidar observations of height profiles of dust optical properties (backscatter, extinction, lidar ratio, depolarization ratio) are compared. The lidar-derived profiles of particle extinction and backscattering have to be in agreement with Sun photometer observations of the spectrally resolved par- ticle optical depth. Such comparisons are presented in this paper. In the second step of the column closure studies, the optical properties measured at ambient conditions (lidar, photometer) are compared with results that are derived from airborne in situ observations of microphysical, chemical and optical properties made at non-ambient conditions (Petzold et al., 2008; Weinzierl et al., 2008). A unique set of sophisticated techniques was used in SAMUM to measure the entire dust size distribution. The radiative closure experiment completes the SAMUM column closure efforts and makes use of the lidar profiles to quantify the radiative effects of Saharan dust (Bierwirth et al., 2008; Otto et al., 2008). SAMUM lidar data are also used in the papers dealing with the mesoscale Saharan dust transport and satellite remote sensing of dust over land (Dinter et al., 2008; Heinold et al., 2008; Kahn et al., 2008; Knippertz et al., 2008).

In this contribution, we give an overview of the basic lidar observations at Ouarzazate. We present case studies, comparisons and statistical results regarding dust layer height and optical properties (optical depth, extinction, backscatter, lidar ratio, Ångström exponent). Further SAMUM lidar observations are presented by Esselborn et al. (2008), Freudenthaler et al. (2008), Heese et al. (2008) and Ansmann et al. (2008). Ansmann et al. (2008) discuss the impact of dust particles on heterogeneous ice formations and show lidar observations of water and mixed-phase clouds that formed within the Saharan dust layer.

The paper is organized as follows. In Section 2, the instrumentation and the lidar retrieval methods are presented in some detail. Observations (case studies, statistical analysis) are discussed in the Section 3. Meteorological conditions are briefly described. An extended meteorological overview is given by Knippertz et al. (2008). Section 3 also contains a survey of published desert dust lidar ratios and respective comparisons with SAMUM results. Section 4 summarizes the main findings of the lidar observations.

\section{Instrumentation}

\subsection{Lidar}

Three Raman lidars were operated at the airport of Ouarzazate during SAMUM 2006. Ouarzazate $\left(30.9^{\circ} \mathrm{N}, 6.9^{\circ} \mathrm{W}\right.$, 1133-m height a.s.1.) is located in a flat basin bounded by two almost parallel steep mountain chains of the High Atlas (more than $4000 \mathrm{~m}$ high) and the Anti-Atlas/Jebel Saghro (up to $2700 \mathrm{~m}$ high). The most powerful SAMUM lidar is the six-wavelength aerosol lidar backscatter extinction lidar-ratio temperature humidity profiling apparatus (BERTHA) of the Leibniz Institute for Tropospheric Research, IfT (Althausen et al., 2000). The Meteorological Institute of the Munich University (MIM) operated two lidars. Portable lidar system (POLIS) is a small lidar, transmitting linearly polarized laser pulses at $355 \mathrm{~nm}$ and can either be used as a Raman lidar or, alternatively, as a polarization lidar 
(Heese et al., 2002; Freudenthaler et al., 2008). Multiwavelength lidar system (MULIS) is a polarization-Raman lidar transmitting laser pulses at 355, 532 and $1064 \mathrm{~nm}$ wavelength (Wiegner et al., 1995; Freudenthaler et al., 2008). During SAMUM, Raman signals were only measured at $387 \mathrm{~nm}$ (nitrogen Raman signals). Main goal of MULIS are highly precise measurements of the depolarization ratio (Freudenthaler et al., 2008). The airborne lidar of DLR is a 532-nm HSRL with polarization-sensitive detection at 532 and $1064 \mathrm{~nm}$ (Esselborn et al., 2008; Freudenthaler et al., 2008). In the following, we briefly summarize the BERTHA characteristics.

The six-wavelength lidar transmits pulses at 355, 400, 532, 710,800 and $1064 \mathrm{~nm}$ with a repetition rate of $30 \mathrm{~Hz}$. Four lasers (two Nd:YAG and two Ti:Sa lasers) are employed. One $\mathrm{Nd}$ :YAG laser transmits pulses at 355, 532 and $1064 \mathrm{~nm}$, the other Nd:YAG is used for optical pumping of the two Ti:Sa lasers. One of the Ti:Sa lasers transmits pulses at $710 \mathrm{~nm}$ and the other, pulses at 400 and $800 \mathrm{~nm}$. The six laser beams are aligned onto one optical axis. A scanning unit outside the container permits measurements from $90^{\circ}$ to $-90^{\circ}$ zenith angle (i.e. from west to east during SAMUM). Most observations are done at a zenith angle of $45^{\circ}$ at daytime (to the west) and at $0^{\circ}-$ $5^{\circ}$ at nighttime. Backscattered light is collected with a $0.53-\mathrm{m}$ Cassegrain telescope.

A sketch of the multichannel receiver is shown in Fig. 1. The receiver unit separates the elastic backscatter signals (for the six laser wavelengths), vibrational-rotational Raman signals at 387 and $607 \mathrm{~nm}$ (nitrogen) and $660 \mathrm{~nm}$ (water vapour) and pure rotational Raman signals (Stokes and anti-Stokes lines) from oxygen and nitrogen around $532 \mathrm{~nm}$ (Mattis et al., 2002b; Arshinov et al., 2005). Dichroic beamsplitters, narrow-band interference filters and a double-grating monochromator (Arshinov et al., 2005) are used to separate the different signals. The grating setup for separating two temperature-sensitive Raman signals includes another $532 \mathrm{~nm}$ elastic backscatter channel to allow the full application of the aerosol Raman lidar method (described below) to the ro- tational Raman signals. This is important because the rotational Raman signals are strong enough to be detected at daytime, in the presence of a bright sky background. The vibrational Raman signals are too weak to be detected at daytime. Thus, the rotational Raman signals enable to determine dust extinction coefficients and extinction-to-backscatter ratios at daytime and nighttime, whereas the vibrational Raman signals permit us to determine these parameters at nighttime only, however, at two wavelengths ( 355 and $532 \mathrm{~nm}$ ).

At $710 \mathrm{~nm}$, the cross- and parallel polarized components of the backscattered light are measured separately. Photomultiplier tubes (PMTs) are used as detectors. For the elastic backscatter signals $(400,532,710,800 \mathrm{~nm})$ the analogue PMT output is pre-amplified and digitized (12 bit, $10 \mathrm{MHz}$ ), whereas the 355and 1064-nm elastic backscatter signals, the Raman signals and a part of the backscattered 532-nm photons (primary wavelength of the 607 and $660 \mathrm{~nm}$ Raman signals) are detected with photoncounting PMTs, operated at $300 \mathrm{MHz}$.

The raw signals are stored with range and time resolutions of 7.5-60 $\mathrm{m}$ and $10-30 \mathrm{~s}$, respectively. All raw signal profiles are corrected for deadtime effects and for sky background noise before the data are further processed to obtain the dust optical properties.

A detailed description of the techniques applied to analyse multiwavelength Raman lidar observations can be found in Ansmann et al. (2002b), Wandinger et al. (2002), Franke et al. (2003), Mattis et al. (2004) and Ansmann and Müller (2005). Esselborn et al. (2008) recently presented the methods for aerosol backscatter, extinction and depolarization profiling with the DLR Falcon HSRL. Here, we briefly summarize the retrieval methods for the ground-based Raman lidars.

The profiles of the volume extinction coefficient of the particles at 355 and $532 \mathrm{~nm}$ are calculated from the measured profiles of the Raman signals. In the case of the rotational Raman signals, the sum of the two signals is used. Signal averaging of 30-120 min and vertical smoothing of the signal profiles with

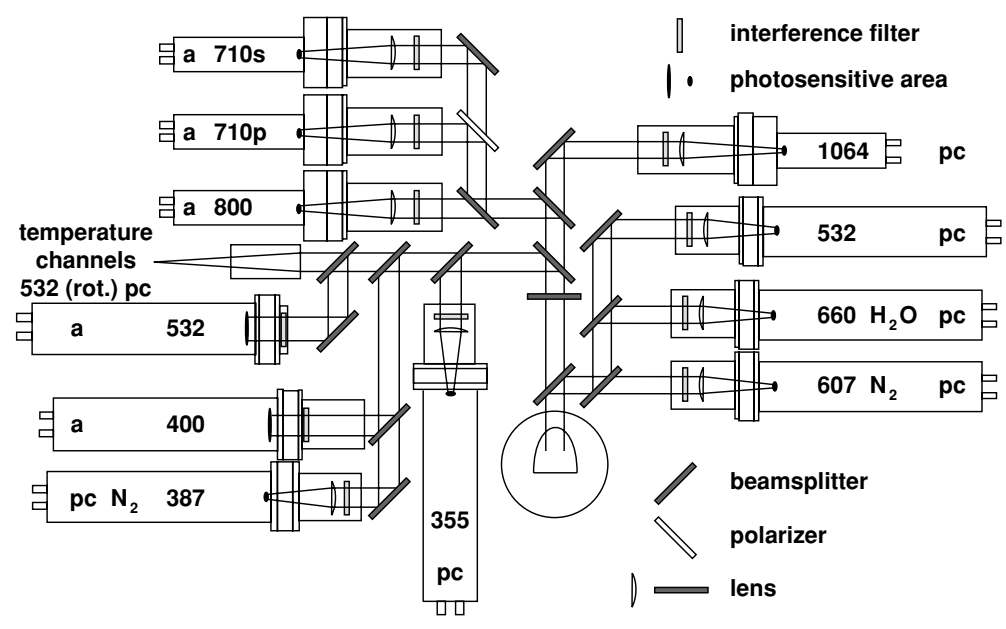

Fig. 1. Sketch of the BERTHA receiver. The 14-channel lidar measures elastic backscatter signals $(355,400,532,710,800,1064 \mathrm{~nm})$, vibrational Raman signals $(387,607$, $660 \mathrm{~nm}$, nitrogen $\mathrm{N}_{2}$, water vapour $\mathrm{H}_{2} \mathrm{O}$ ), and rotational Raman signals around $532 \mathrm{~nm}$ (temperature channels, includes another $532 \mathrm{~nm}$ elastic backscatter channel). The number denotes the detection wavelength of the respective photomultiplier tube, abbreviations a and pc describe the kind of signal detection (analogue or photon counting), s and $\mathrm{p}(710 \mathrm{~nm})$ denote channels for detection of cross and parallel polarized light, respectively. 
window lengths from 300 (lower heights) to 1200-2400 m (upper part of optically dense dust layers) was necessary to reduce the statistical errors of the extinction coefficients to values of $5 \%-25 \%$. Systematic uncertainties caused by the removal of Rayleigh-scattering and air-density effects from the backscatter signals are on the order of $5 \%-10 \%$.

It is interesting to note that in the case of the airborne HSRL, extinction profiling is based on measurements of almost pure Rayleigh backscatter signals. Rayleigh backscattering is more than two orders of magnitude larger than vibrational Raman backscattering and thus permits day and night operations with high temporal resolution of few seconds to few minutes. Signal smoothing of several hundreds of meters is, however, also necessary here to reduce the influence of signal noise (Esselborn et al., 2008).

The profiles of the volume backscatter coefficients at 355 and $532 \mathrm{~nm}$ are determined from the profile of the ratio of the elastic backscatter signal (at 355 or $532 \mathrm{~nm}$ ) to the corresponding nitrogen Raman signal (387 or $607 \mathrm{~nm}$ ). In a similar way, the $1064 \mathrm{~nm}$ signal and the $607 \mathrm{~nm}$ nitrogen Raman signal are combined to calculate the dust backscatter coefficient at $1064 \mathrm{~nm}$. The use of a photon-counting PMT at $1064 \mathrm{~nm}$ enables us to accurately measure Rayleigh backscattering at this wavelength in the aerosol-free upper troposphere and lower stratosphere. The signal calibration height was typically set to $7-9 \mathrm{~km}$ height above ground level (a.g.1.), and a total-to-Rayleigh backscatter ratio of 1.05 was assumed in the data analysis. Calibration uncertainties are estimated to be less than $10 \%$ at $1064 \mathrm{~nm}$.

As mentioned, these retrievals can only be applied to the nighttime signals. The advantage of using signal ratios is that laser-beam receiver-field-of-view (RFOV) overlap effects (as discussed below) widely cancel out so that the profile of the backscatter coefficient (indicating the dust layering) is trustworthy to low heights above the lidar. Furthermore, input parameters such as the lidar ratio that is used to correct for attenuation effects are not needed. Similarly, the aerosol and Rayleigh signals at $532 \mathrm{~nm}$ are used in the case of the HSRL to calculate the backscatter coefficients (Esselborn et al., 2008). Once the profiles of the extinction and the backscatter coefficients are available, the vertical profile of the extinction-to-backscatter ratio is obtained in addition.

Alternatively, the elastic backscatter signals alone can be used to compute the volume backscatter-coefficient profile by applying the Fernald method (Fernald, 1984) and to estimate, in a subsequent step, the corresponding extinction coefficients from the backscatter coefficients. In the Fernald method, the extinctionto-backscatter ratio is an input parameter. The advantage of the method is that extinction and backscatter profiles can be determined with high temporal and vertical resolution at nighttime as well as at daytime.

The relative statistical error of the backscatter coefficients is generally of the order of 5\%-10\%. Systematic effects (calibration, Rayleigh scattering correction) are estimated to be about

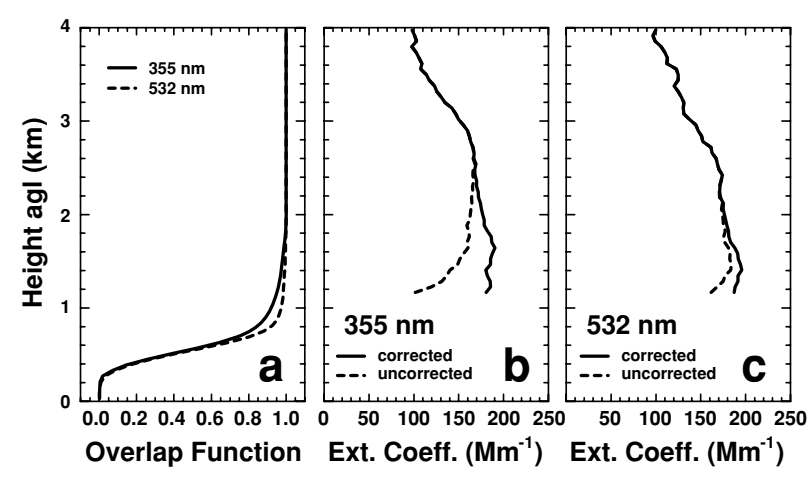

Fig. 2. (a) Lidar overlap function as a function of height above ground (a.g.l.), computed from the 355 and $387 \mathrm{~nm}$ signals (solid line) and from the 532 and $607 \mathrm{~nm}$ signals (dashed line) measured during a clear night (11 May) and dust extinction coefficients computed from $387 \mathrm{~nm}$ (b) and $607 \mathrm{~nm}$ Raman signals (c) observed on 15 May. The overlap effect is ignored in the case of the dashed lines and considered in the case of the solid lines in (b) and (c).

$5 \%-10 \%$ in the desert environment. The extinction coefficients estimated from the backscatter coefficients are also obtained with comparably high accuracy of $10 \%-20 \%$, because the dust lidar ratio (main input parameter) is well known from the Raman and HSRL observations and does not introduce large uncertainties in this homogeneous environment. In polluted continental areas, where the relative contributions of maritime particles, fresh and aged urban haze and smoke particles to the observed aerosol are unknown and may vary strongly with time and height, the uncertainty in the assumed lidar ratio profile and in the extinction estimation from backscatter profiles is usually very high.

The extinction measurements with ground-based lidars are biased by the incomplete overlap of the laser beam with the RFOV in the near range which is about 100-200, 300-700 and about 2000-3000 $\mathrm{m}$ in the case of POLIS, MULIS and BERTHA (most channels), respectively. The RFOV of BERTHA is $0.8 \mathrm{mrad}$ for most of the channels and only $0.1-0.15 \mathrm{mrad}$ for the grating monochromator (rotational Raman channels and corresponding $532 \mathrm{~nm}$ elastic backscatter channel). The full laser-beam RFOV overlap is reached in a distance of about 4000-5000 $\mathrm{m}$ from the lidar in the case of the rotational Raman signals.

Fortunately, the overlap effect can partly be corrected as shown in Fig. 2. During clear, almost dust-free nights, the overlap profile of the lidar can be determined by applying the procedure suggested by Wandinger and Ansmann (2002). Correction of the overlap effect by means of the measured overlap profile enables us to obtain trustworthy extinction values down to 700$1000 \mathrm{~m}$ at optimum conditions with a stable overlap profile over days. However, this was not the case during SAMUM. Because of permanent air conditioning problems in the BERTHA lidar container (with four lasers and many data acquisition systems producing a lot of heat), the overlap characteristics changed significantly from day to day in this desert environment. As a 


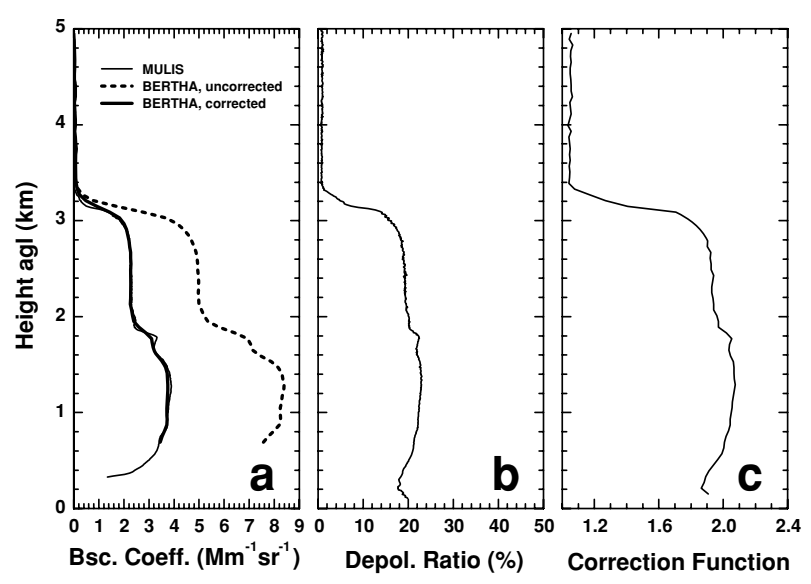

Fig. 3. Influence of the polarization-sensitive detection efficiency of the $532 \mathrm{~nm}$ elastic backscatter channel (532, pc, Fig. 1) on the retrieval of the dust backscatter coefficient. (a) The dashed curve shows the uncorrected case, the thick solid curve is obtained from the corrected $532 \mathrm{~nm}$ signals. For comparison, the profile of the dust backscatter coefficient computed from MULIS data is shown (thin solid line). In the signal correction, the profile of the $532 \mathrm{~nm}$ volume depolarization ratio measured with MULIS, shown in (b), is required to calculate $K(z)$ (eq. 1), shown in (c). For correction, the $532 \mathrm{~nm}$ signals (as function of height $z$ ) are divided by $K(z)$, then the backscatter coefficients are calculated from the corrected signals.

consequence, BERTHA signals measured at heights below $2 \mathrm{~km}$ a.g.1. were often not reliable enough to be further used in the extinction, backscatter and lidar ratio retrievals.

A trustworthy correction of the overlap was usually possible down to $150 \mathrm{~m}$ height a.g.l. in the case of POLIS and to $350 \mathrm{~m}$ height a.g.l. in the case of MULIS. No overlap problems occur for a downward looking lidar aboard an aircraft flying at 8$12 \mathrm{~km}$ height a.s.l.. The full overlap is reached well above the dust layers.

Finally, another error source has to be discussed which may play a critical role in desert environments (Mattis et al., 2002a). Our polarization-dependent calibration measurements at Leipzig, Germany, revealed that the efficiency factor $\eta$ of most detection channels of BERTHA is polarization sensitive. $\eta$ describes the transmission of light from the primary mirror of the telescope to the photomultiplier. For most channels, however, this polarization-dependent effect is small and can be ignored in the retrieval. The exception is the $532 \mathrm{~nm}$ pc channel in Fig. 1.

The efficiency factor $\eta_{\|}$for the parallel-polarized component (parallel with respect to the plane of polarization of the emitted linearly polarized laser light) is about 5-7 times smaller than the related cross-polarized efficiency factor $\eta_{\perp}$. To properly account for this effect, we follow the procedure suggested by Mattis et al. (2002a). The consequence of the effect is illustrated in Fig. 3a. Without correction, the computed $532 \mathrm{~nm}$ backscatter coefficient in the dust layer is, by a factor of two, larger than the true one (MULIS data). The measured signal strengths are corrected by dividing the $532 \mathrm{~nm}$ signals $P_{532}(z)$ by $K(z, \lambda)$ given by

$K(z, \lambda)=\frac{D(\lambda) \delta(z, \lambda)+1}{\delta(z, \lambda)+1}$.

$K(z, \lambda)$ for height $z$ and wavelength $\lambda$ of the 532-nm elastic backscatter channel (532, pc, Fig. 1) is shown in Fig. 3c. $D=\eta_{\perp} / \eta_{\|}$is obtained from the calibration measurement at Leipzig. For the observation shown in Fig. 3, $D=6.76$. The required volume depolarization ratio $\delta(z)$ at $532 \mathrm{~nm}$, the ratio of the cross polarized to the parallel polarized total (Rayleigh + particle) backscatter coefficient, is provided by MULIS (Freudenthaler et al., 2008). The volume depolarization ratio for the measurement on 3 June 2006, is shown in Fig. 3b. Remaining uncertainties in the corrections are estimated to be of the order of a few percent. Profiles of the volume depolarization ratio for all available measurement days were required from the MULIS observations to obtain a trustworthy 532-nm backscatter data set. MULIS was operated in a distance of about $10 \mathrm{~m}$ from BERTHA.

It should be mentioned that the other two $532 \mathrm{~nm}$ channels of BERTHA do not show this polarization-dependent effect and can thus be used to check the quality of the correction. This strong polarization effect on our main $532 \mathrm{~nm}$ signal was not visible during foregoing campaigns such as LACE 98 (Wandinger et al., 2002) and the Indian Ocean Experiment (INDOEX, Franke et al., 2003). This may partly be caused by the fact that anthropogenic aerosols which produce very low depolarization ratios prevailed during these campaigns. However, during these campaigns, the polarization effect was also not visible in cirrus clouds. The most reasonable explanation is therefore that one of the mirrors that directs the light to the $532 \mathrm{~nm}$ PMT degraded significantly during the last 6 years, with the result of an increased sensitivity of this channel to the state of polarization of the incoming light.

\subsection{Sun photometry}

The Leipzig lidar group run an Aerosol Robotic Network (AERONET) station. The station usually takes data at Leipzig, Germany, and was equipped with an additional long-wavelength channel at $1640 \mathrm{~nm}$ for improved dust observations. The photometer run from 11 May to 10 June 2006 (see AERONET web page, (Holben et al., 1998)). The SAMUM AERONET Sun photometer measured the particle optical depth in eight channels at 340, 380, 440, 500, 675, 870, 1020 and $1640 \mathrm{~nm}$ and sky radiances at different almucantar angles at four of these wavelengths. The Sun photometer was calibrated at Goddard Space Flight Center (AERONET Headquarter), Greenbelt, MD, before (winter of 2005) and after the SAMUM campaign (autumn of 2006). Another Sun photometer of the Munich University was mounted at the Ouarzazate field site and took data almost continuously (Toledano et al., 2008). The comparison of the two photometers yield that the uncertainty in the optical depth measured 
with the AERONET photometer is less than 0.01-0.02 at wavelengths $<500 \mathrm{~nm}$ and $<0.01$ for the larger wavelengths.

From the particle optical depths, the Ångström exponent (Ångström, 1961,1964) is calculated. The Ångström exponent, which is defined as the slope of the logarithm of aerosol optical depth versus the logarithm of wavelength, is commonly used to characterize the wavelength dependence of the aerosol optical depth and to provide some basic information on the aerosol size distribution (Eck et al., 1999). In Section 3, we present an overview of the one-month observations.

\subsection{Radiosounding}

A morning sonde (around 1030 UTC $=$ Local Time, LT) and an evening sonde (shortly after sunset) were regularly launched. The radiosonde ascents provide height profiles of air pressure, temperature, relative humidity, horizontal wind speed and direction up to 15-20 km height. 40 Vaisala RS92 sondes were used, another 10 were sondes of type RS80. This latter sonde type measures temperature, pressure and humidity only.

\section{Observations}

Figure 4 shows the dust conditions during SAMUM 2006 in terms of the particle optical depth at 380,500 and $1020 \mathrm{~nm}$ and respective Ångström exponents. Two major dust outbreak periods occurred during SAMUM, the first one lasted from 12-22 May 2006, and the second one began on 2 June 2006. A detailed discussion of the meteorological conditions during SAMUM can be found in Knippertz et al. (2008).

On 11-14 May, an upper-level short-wave trough moved across northwestern Africa and triggered the formation of a lowlevel cyclone east of the Atlas mountains. Dusty air from eastern and central Algeria was advected into southern Morocco, along the northern flank of the low-level cyclone. Between 16-21 May, northwestern Africa was dominated by an upper-level ridge and calm sunny weather. The persistent surface high with the core over the eastern Atlas steered air from eastern and central Algeria towards Morocco. Optimum conditions for the observation of pure dust were given during this period.

In the beginning of June, an upper-level ridge strengthened and surface pressure rose quickly after a period with changing weather conditions and thunderstorm activity. Although southern Morocco was influenced by air masses from the north and west in the beginning of this period, the strengthening of the lowlevel anticyclone led to advection of dustier air masses from the east. However, until 4 June, the development of deep convection over the Atlas caused less defined advection conditions as was the case during the first dust period. Mixing of Saharan air with maritime and anthropogenically polluted air from northerly and westerly directions (and from the surroundings) cannot be excluded and may have influenced the observations to some extent.

In the first part of this section we present four case studies. Two measurements (15 and 19 May) were conducted during the first dust period, the other two observations ( 3 and 4 June) during the second dust phase.

\subsection{Case studies}

Figure 5 shows 72-h backward trajectories arriving at Ouarzazate on 15 May 2006, 2100 UTC (a); on 19 May, 1100 UTC (b) and 3 June 2006, 0500 UTC (c) and 4 June, 1100 UTC (d). On 15 May, we compared the observations of all three ground-based Raman lidars during a heavy dust period. On 3 June, the night flight of the FALCON aircraft was used to compare the observations
Fig. 4. One-month AERONET Sun photometer observations (11 May-10 June 2006) of optical depths (top panel) and Ångström exponents (bottom panel) for the wavelength pairs 380 and $500 \mathrm{~nm}$ and 500 and $1020 \mathrm{~nm}$. Light yellow areas indicate periods with dust advection from the Sahara leading to optical depths $>0.2$ at $500 \mathrm{~nm}$ and Ångström exponents $<0.4$, both indicated by horizontal lines.

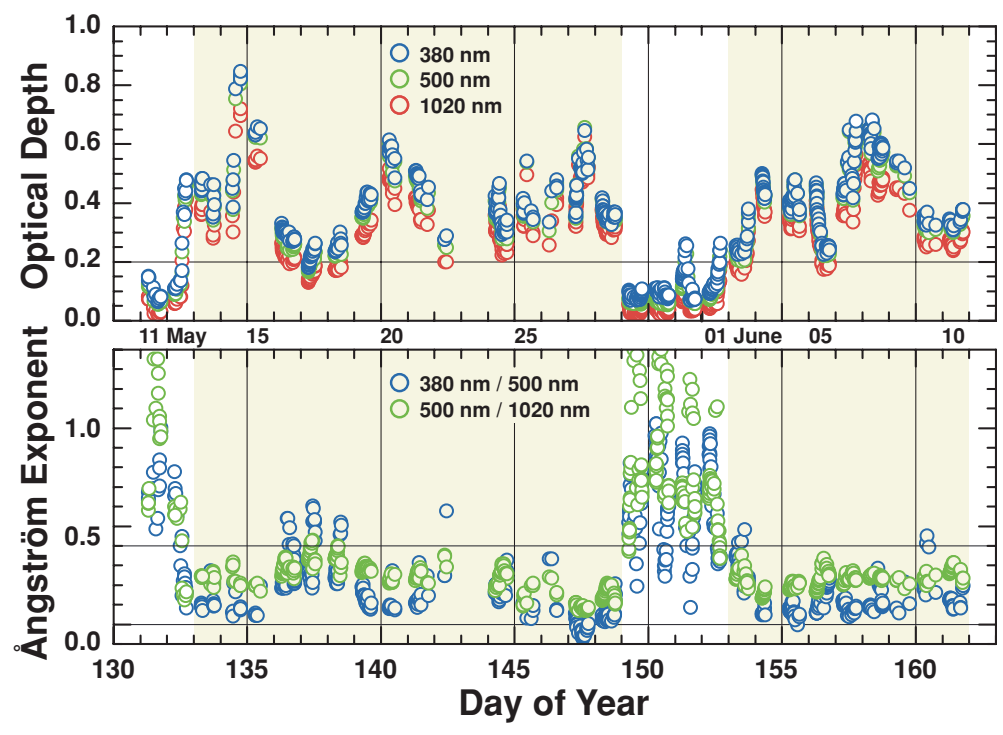



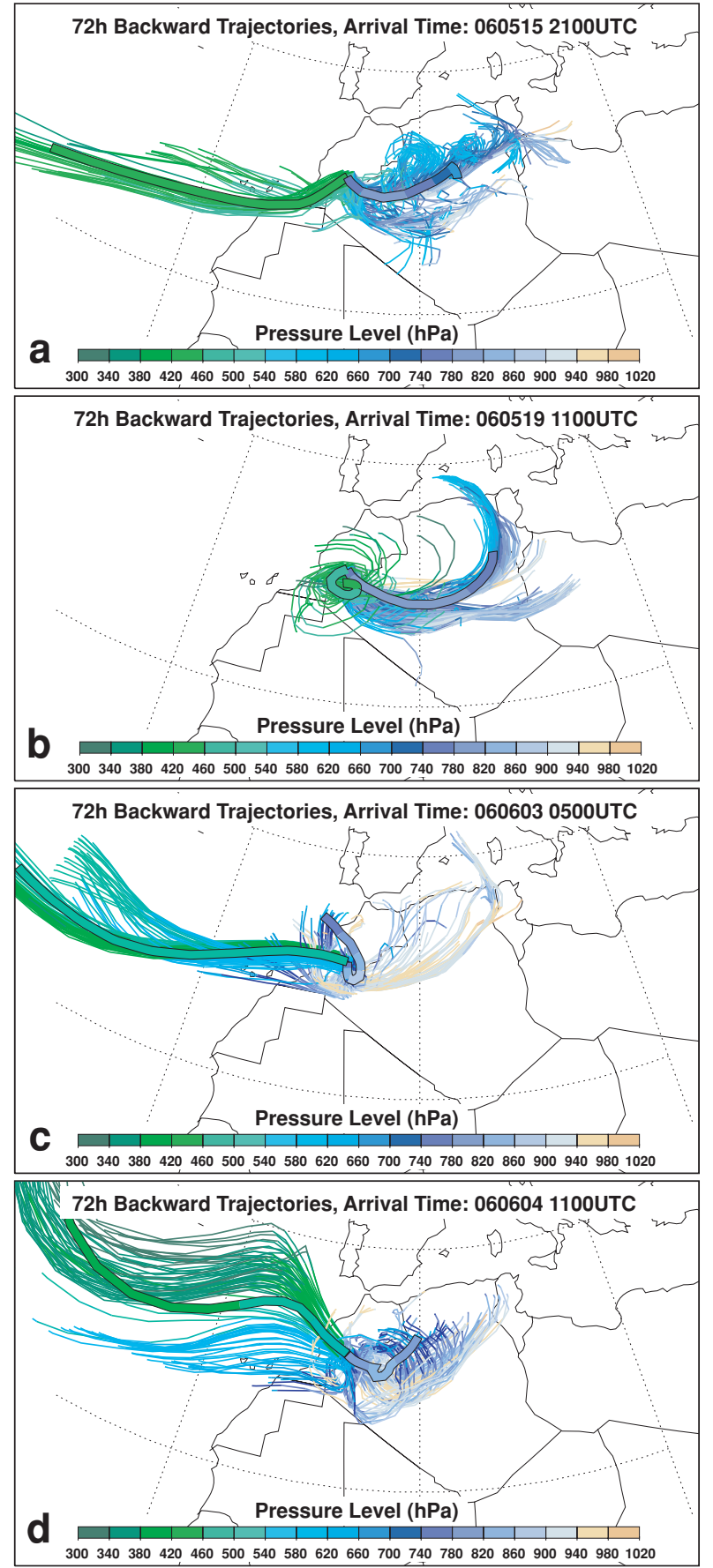

Fig. 5. Three-day backward trajectories ending over the lidar site on (a) 15 May, 2100 UTC, (b) 19 May, 1100 UTC, (c) 3 June, 0500 UTC and (d) 4 June, 1100 UTC. Trajectories are calculated for nine arrival points (for each longitude-latitude combination of $30^{\circ}, 30.5^{\circ}$ and $31^{\circ} \mathrm{N}$, and $6.5^{\circ}, 7.0^{\circ}$ and $7.5^{\circ} \mathrm{W}$, respectively) and 30 vertical levels up to $400 \mathrm{hPa}$. Thick lines indicate the ensemble mean trajectories for the dust layer (transport mainly from easterly directions) and for the lower free troposphere (transport mainly from westerly directions). The colour indicates the actual pressure level of the air parcel during its travel along the trajectory. The dotted lines show longitudes $\left(20^{\circ} \mathrm{W}, 0^{\circ}\right.$, $\left.20^{\circ} \mathrm{E}\right)$ and latitudes $\left(20^{\circ} \mathrm{N}, 40^{\circ} \mathrm{N}\right)$. of the ground-based systems with the airborne HSRL. 19 May and 4 June are SAMUM key days because of favourable dust and meteorological conditions during satellite overpasses (Kahn et al., 2008).

The trajectories are calculated with the LAGRANTO trajectory algorithm (Wernli and Davies, 1997; Knippertz et al., 2008), which is run with operational analysis data on model levels provided by the European Centre for Medium-Range Weather Forecasts. The backward trajectories are calculated from 3-D wind fields for all gridpoints within the 3-D box from $30^{\circ}-$ $31^{\circ} \mathrm{N}$ to $6.5^{\circ}-7.5^{\circ} \mathrm{W}$ and from the ground to $400 \mathrm{hPa}$. From the computed 270 trajectories ensemble mean backward trajectories for the dust layer (from the surface to the dust layer top) and the lower free troposphere (from the dust layer top to the $400 \mathrm{hPa}$ level, $7-7.5 \mathrm{~km}$ height a.s.1.) are determined. The ensemble means represent the main air flow in the two different layers.

As can be seen, dust was advected directly from Algeria on 15 and 19 May. Trajectories in the dust layer were over desert areas during the last three days before the arrival at Ouarzazate. Figure 4 indicates high particle optical depths of $0.5-0.8$ on 14 and 15 May. On 3 June, the air flow in the dust layer was not well defined during the built-up phase of the second Saharan dust period. On 4 June, dust was again transported from central Algeria. The air masses above the Saharan dust layer usually were advected from the North Atlantic.

3.1.1. 15 May 2006. Figures $6 \mathrm{~b}$ and d show the time - height displays of the range-corrected signal and the volume depolarization ratio measured with BERTHA in the evening of 15 May. The large numbers of the range-corrected signals in Fig. $6 \mathrm{~b}$ result from the fact that the signal $P(R)$, measured within $10 \mathrm{~s}$ and within a given $15-\mathrm{m}$ height bin, is corrected for the strong decrease with range. In the case of a vertically pointing lidar, range $R$ is equal to height $z$. In the correction $P(R)$ is multiplied by $R^{2}$. A number of $16 \times 10^{11}$ is obtained when 10000 counts are collected from a $15-\mathrm{m}$ range cell at a distance of $4000 \mathrm{~m}$ from the lidar. The logarithm of the range-corrected signal $\ln \left[P(R) R^{2}\right]$ is shown in the colour plots.

A thick and very homogeneous dust layer up to a height of $6 \mathrm{~km}$ a.s.l. is present. Well-mixed conditions were typically found in the early evening as a result of strong convective activity in the boundary layer during daytime (see also Knippertz et al. (2008). High depolarization ratios (green colours in Fig. 6d) are observed throughout the dust layer. Cirrus clouds are present between $11 \mathrm{~km}$ height a.s.l. and the tropopause. The hexagonal crystals produce strong depolarization of the laser light. Water clouds at the top of the dust layer (red in Fig. 6b) consist of spherical scatterers which cause low depolarization ratios (blue in Fig. 6d). The lidar observations in the lowermost 500-1000 $\mathrm{m}$ above the ground (above BERTHA) should be generally interpreted with care because of the high uncertainty in the correction of the laser-beam RFOV overlap effect. 

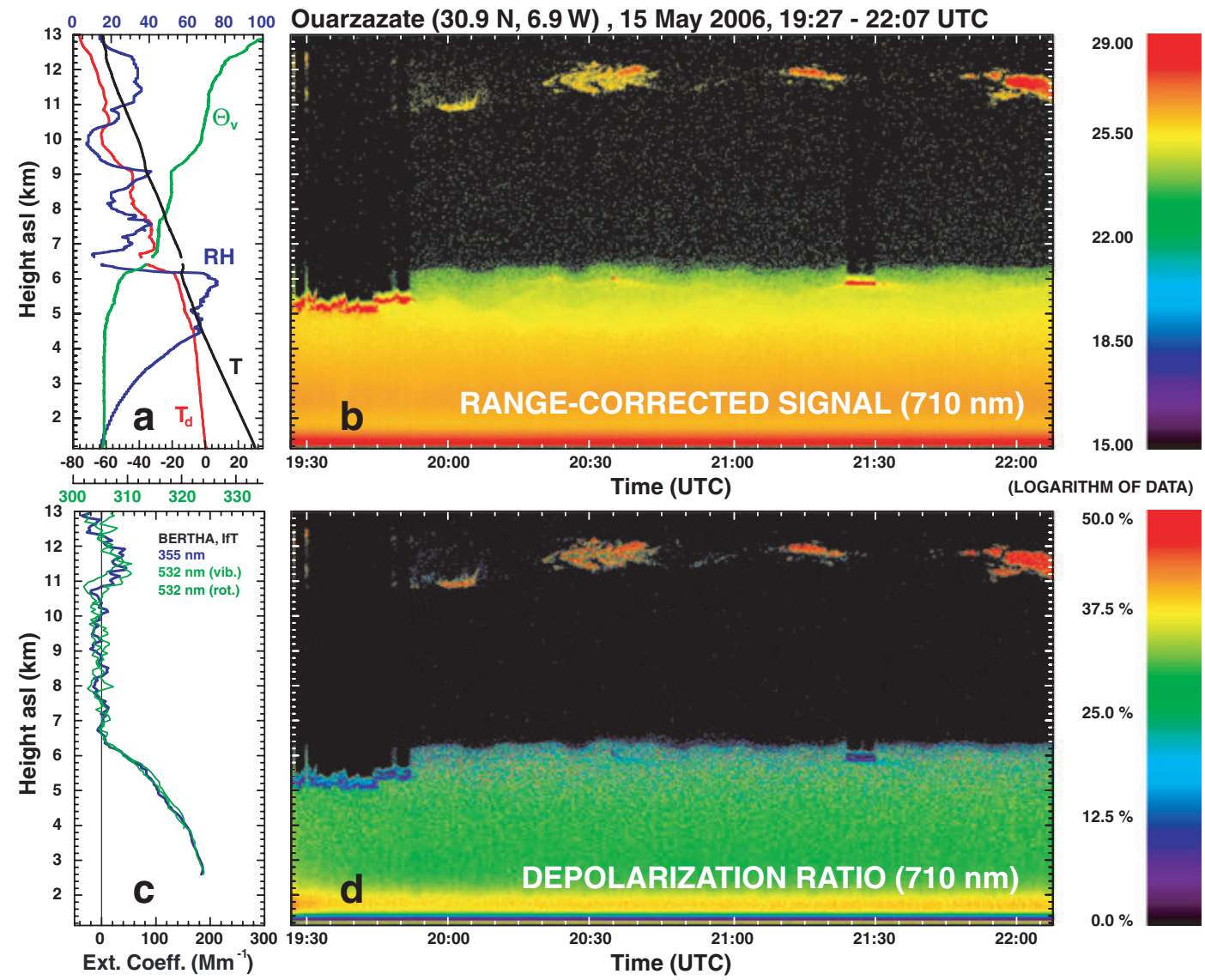

Fig. 6. $5 \mathrm{~km}$ thick Saharan dust layer observed with BERTHA on 15 May 2006, 1927-2207 UTC (= local time) in terms of (b) the range-corrected $710 \mathrm{~nm}$ backscatter signal (in arbitrary units, $10 \mathrm{~s}, 15 \mathrm{~m}$ resolution) and (d) the $710 \mathrm{~nm}$ volume depolarization ratio. The lidar station is at $1133 \mathrm{~m}$ height a.s.l. Left-hand panels show (a) radiosonde profiles (launch at 1948 UTC) of relative humidity $R H$, dew point $T_{\mathrm{d}}$, temperature $T$ and virtual potential temperature $\mathrm{v}$ and (c) height profiles of the dust particle extinction coefficient computed from the vibrational Raman signals ( $355 \mathrm{~nm}$, $532 \mathrm{~nm}$ (vib.)) and from the sum of the two rotational Raman signals ( $532 \mathrm{~nm}$ (rot.)). The extinction coefficients are calculated from cloud-screened signal averages measured from 2025-2125 UTC (600 profiles), smoothed with a vertical window length of $660 \mathrm{~m}$. Cirrus is visible above $10.8 \mathrm{~km}$ height a.s.l. Some water clouds strongly attenuate the laser beam at the top of the dust layer.

The radiosonde profile in Fig. 6a shows a temperature inversion at the top of the dust layer. The relative humidity increases almost up to the base of the water clouds and decreases strongly in the clean troposphere. The virtual potential temperature $\Theta_{v}$ in Fig. 6a is calculated from the profiles of temperature and humidity. An almost height-independent $\Theta_{v}$ up to $4.5 \mathrm{~km}$ height a.s.l. indicates a well-mixed dust layer. The volume extinction coefficients computed from the BERTHA observations (Fig. 6c) indicate vertically smooth extinction conditions in the dust layer. Values range from $100-200 \mathrm{Mm}^{-1}$ in the main part of the dust layer. No wavelength dependence of light extinction is visible.

Figure 7 shows a comparison of extinction (a) and lidar ratio profiles (b) derived from the observations with the three groundbased Raman lidars. In addition, profiles of the Ångström exponents computed from the BERTHA backscatter (c, BSC) and extinction profiles (d, EXT) are shown. A very good agreement between the different lidar observations is found. The lidar ratio profiles also indicate a well-mixed Saharan dust layer. Lidar ratios are around $55 \mathrm{sr}$ at $355 \mathrm{~nm}$ during this heavy dust outbreak. The lidar ratios at $532 \mathrm{~nm}$ seem to be higher. But the error bar is large because of the uncertainty in all the corrections (overlap, signal corrections) applied and thus the difference should be handled with care. 355 and $532 \mathrm{~nm}$ lidar ratios are equal above $4 \mathrm{~km}$ height a.s.l.. The Ångström exponents are around 0-0.5 (backscatter) and zero (extinction). The extinction-related Ångström exponents agree well with the AERONET observations taken before sunset (see blue and green circles at the bottom of Fig. 7d).

According to Ansmann et al. (2002b), the extinction-related Ångström exponent is the sum of the backscatter-related Ångström exponent and the lidar-ratio related Ångström exponent. In the case of a vertically homogeneous plume the extinction-related and the optical-depth-related Ångström exponent are the same. Thus, the AERONET value of $0.1-0.2$ for 

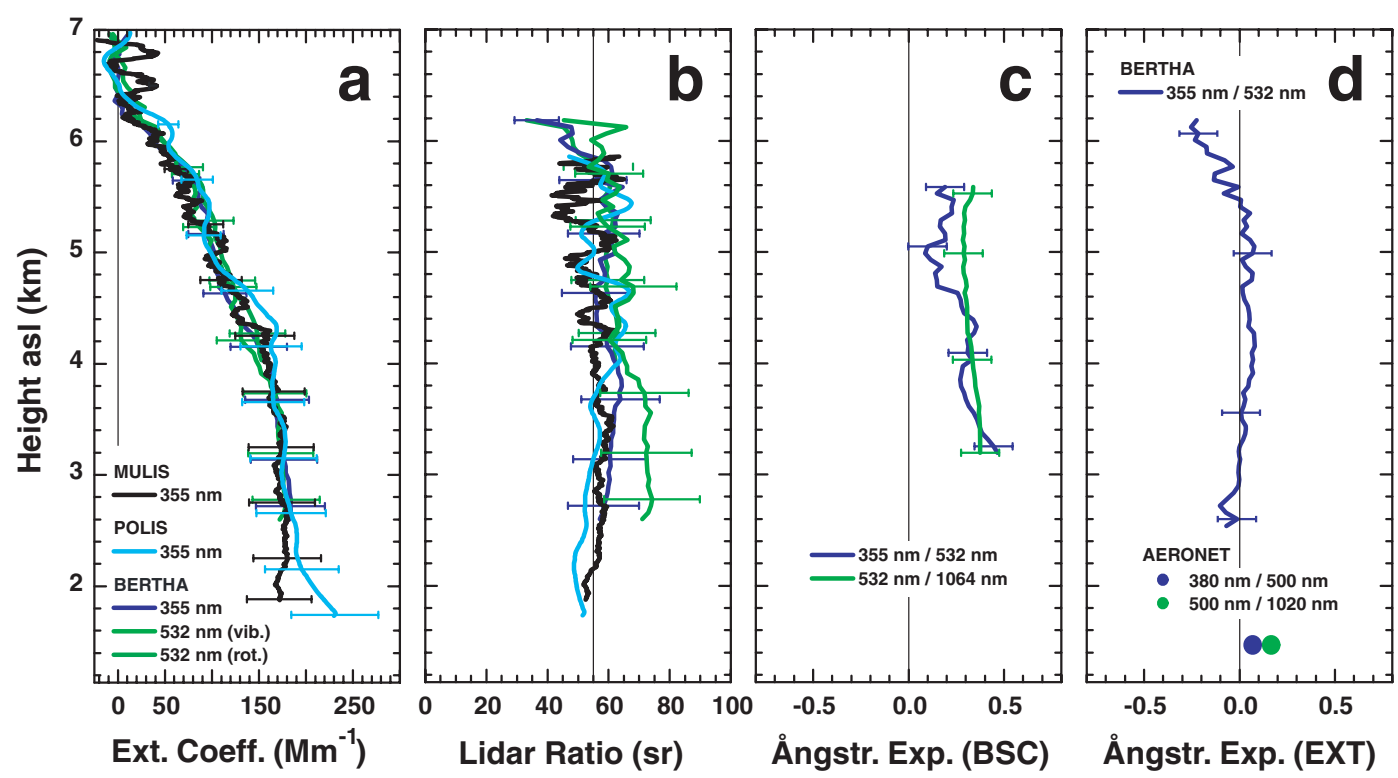

Fig. 7. Cloud-screened 1-h (2025-2125 UTC) mean profiles of (a) the extinction coefficients (BERTHA, MULIS and POLIS), (b) the respective lidar ratios at 355 and $532 \mathrm{~nm}$, (c) and (d) Ångström exponents computed from BERTHA observations. BSC (c) and EXT (d) denote values calculated from backscatter and extinction coefficients, respectively. AERONET observations (green and blue circles) are given close to the bottom of (d). Error bars (one standard deviation) include signal noise and several signal corrections. vib. and rot. denote the use of vibrational and rotational Raman signal profiles (BERTHA). Signals are vertically smoothed with window lengths of 300-600 (lower heights) and 300-2400 m (upper part of the dust layer).

the Ångström exponent computed from the 500 and $1020 \mathrm{~nm}$ optical depths and the lidar-derived value of $0.1-0.5$ for the backscatter-related Ångström exponent point to an Ångström exponent for the lidar ratio of 0 to -0.3 . This value corresponds to a lidar ratio at $1064 \mathrm{~nm}$ that is about $0 \%-20 \%$ larger than the $532 \mathrm{~nm}$ lidar ratio.

The comparison of the lidar-derived and photometer-derived dust optical depths is shown in Fig. 8. The lidar values are

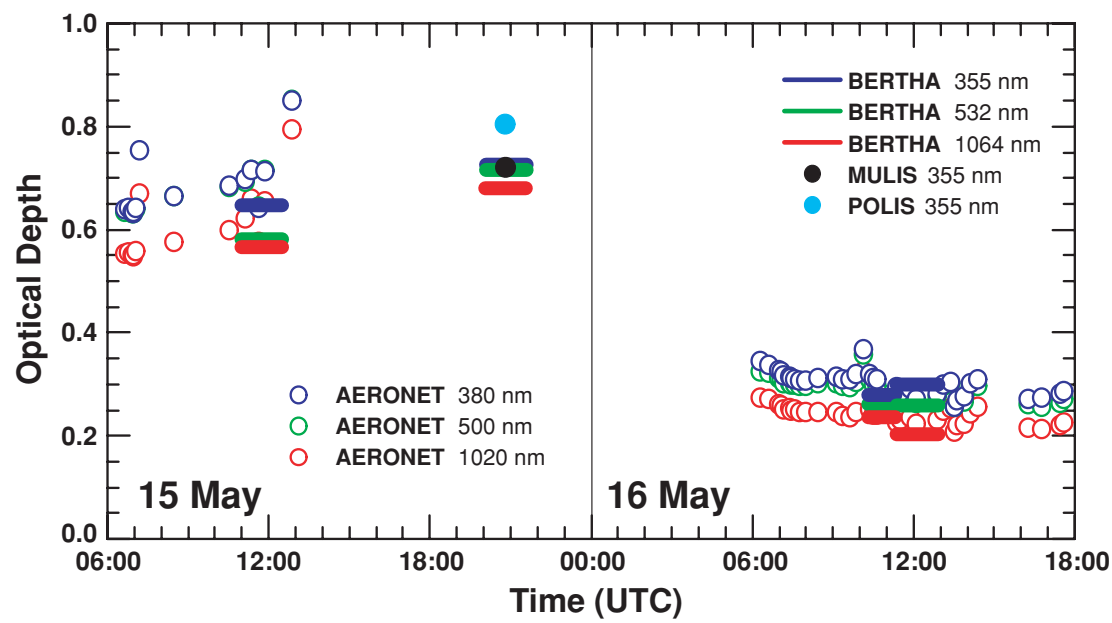

Fig. 8. Comparison of lidar observations (BERTHA, MULIS, POLIS) of the dust optical depth with respective AERONET photometer observations on 15-16 May 2006. Shown is the optical depth at three wavelengths measured with Sun photometer (open circles) and the lidar-derived optical depth at the three wavelength of 355, 532, and $1064 \mathrm{~nm}$, computed from extinction and backscatter profiles. Profiles were extended to ground level by assuming no further height variation from the last (lowermost) trustworthy height bin. A lidar ratio of $55 \mathrm{sr}$ is assumed in the estimation of the extinction from the backscatter coefficients at daytime and at $1064 \mathrm{~nm}$ at nighttime. Length of the thick horizontal bars indicate the signal averaging period (BERTHA). The uncertainty in the AERONET values is $0.015(380 \mathrm{~nm})$ to $0.005(500,1020 \mathrm{~nm})$ and is $0.05-0.1$ for the lidar values. 

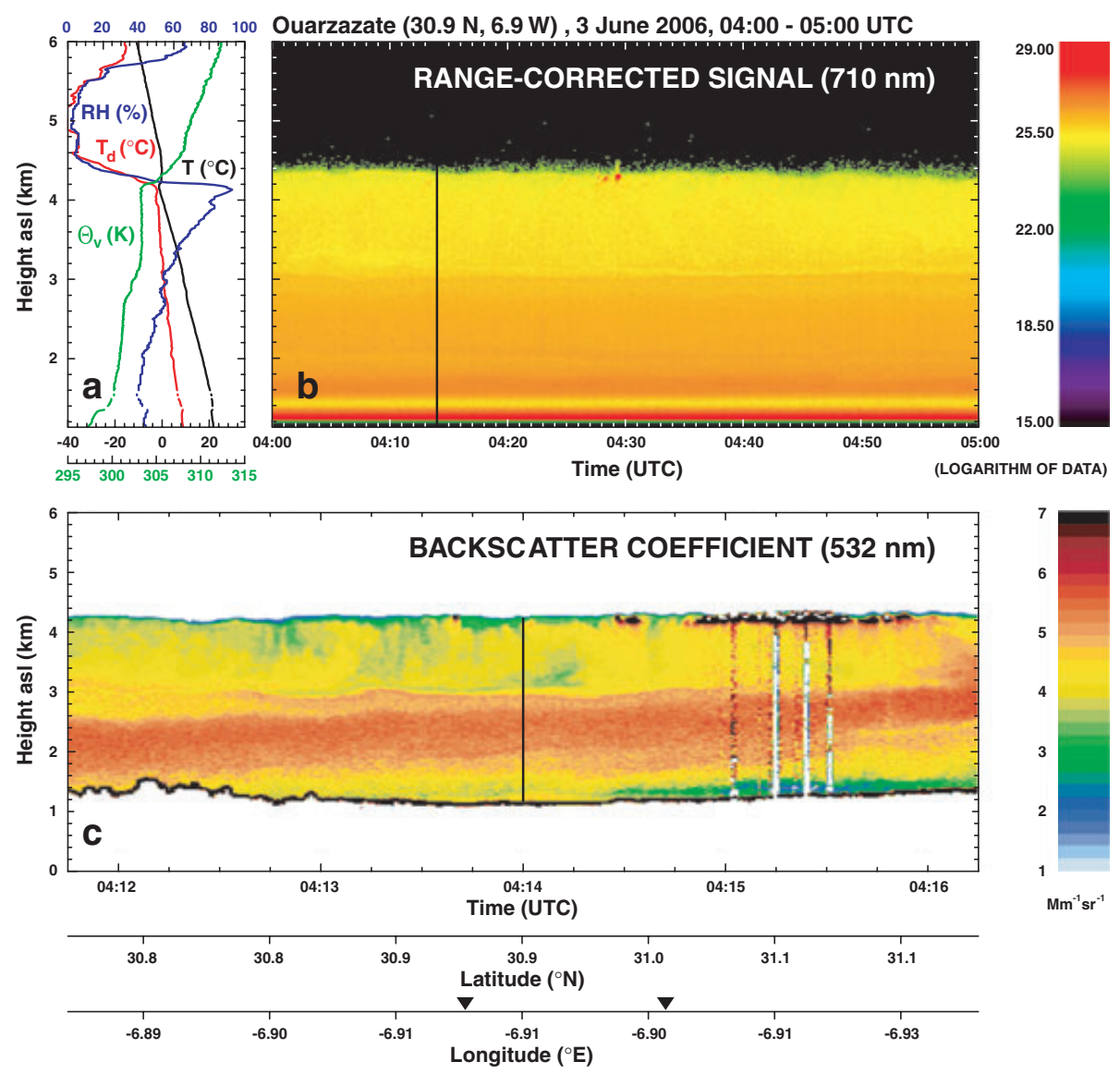

Fig. 9. Saharan dust layer observed with (b) BERTHA in terms of range-corrected signal (uncalibrated, attenuated backscatter) and (c) with the airborne HSRL in terms of the particle backscatter coefficient on 3 June 2006, after 0400 UTC. At 0414 UTC (see vertical black line in b and c) the FALCON aircraft passed the airport station. The radiosonde profiles (launch at 0505 UTC) of relative humidity, dew point, temperature and virtual potential temperature are shown in (a). Triangles (c, longitude axis) indicate slight changes in the flight direction.

calculated as described in Mattis et al. (2004). The nighttime values are exclusively calculated from the extinction profiles assuming a constant extinction coefficient at heights in the near range. The daytime values are calculated from the backscatter coefficient profiles that are multiplied with a lidar ratio of $55 \mathrm{sr}$. Again, in the near range where the overlap correction is rather critical, a constant extinction value is assumed, defined by the backscatter coefficient at the lowest trustworthy height. The agreement between the different observations is good when taking an uncertainty in the lidar values of 0.05 to 0.1 into account, caused by the unknown extinction contribution in the near range. The lidar values are lower than the photometer values on 15 May (around noon). The optical depth of the lowest layer is obviously underestimated.

3.1.2. 3 June 2006. One night flight of the FALCON was conducted during SAMUM to fully compare the observations of the airborne and the ground-based lidars. The Raman lidar technique for extinction profiling can be used best at nighttime when the sky background noise is low. The research aircraft passed the airport station two times, around 0315 and
0414 UTC on 3 June. A 1-h measurement of BERTHA and a 4.5-min observation with the airborne HSRL are shown in Figs. $9 \mathrm{~b}$ and $\mathrm{c}$. The time of the FALCON overpass is marked by black lines at 0414 UTC. Horizontally, very homogeneous conditions are found. The BERTHA and HSRL colour plots are rather similar. Uncalibrated, attenuated total (Rayleigh plus particle) backscatter values are shown in the case of BERTHA, whereas particle backscatter values are presented in the HSRL plot.

According to the backward trajectories (Fig. 5c) the dust transport pattern was not well-defined and may explain the observed two-layer structure (see Knippertz et al., 2008). The air was advected from desert areas in the lower layer and from westerly directions in the upper layer (Esselborn et al., 2008). At the top of the upper layer thin altocumulus forms. The relative humidity is close to $100 \%$ (see Fig. 9a). A vertically inhomogeneous layering was usually observed with lidar in the late night and early morning during SAMUM. This layering typically persisted until the updrafts of the evolving daytime boundary layer reached heights of $2 \mathrm{~km}$ a.g.l., as observed on 19 May and 4 June and discussed below. 


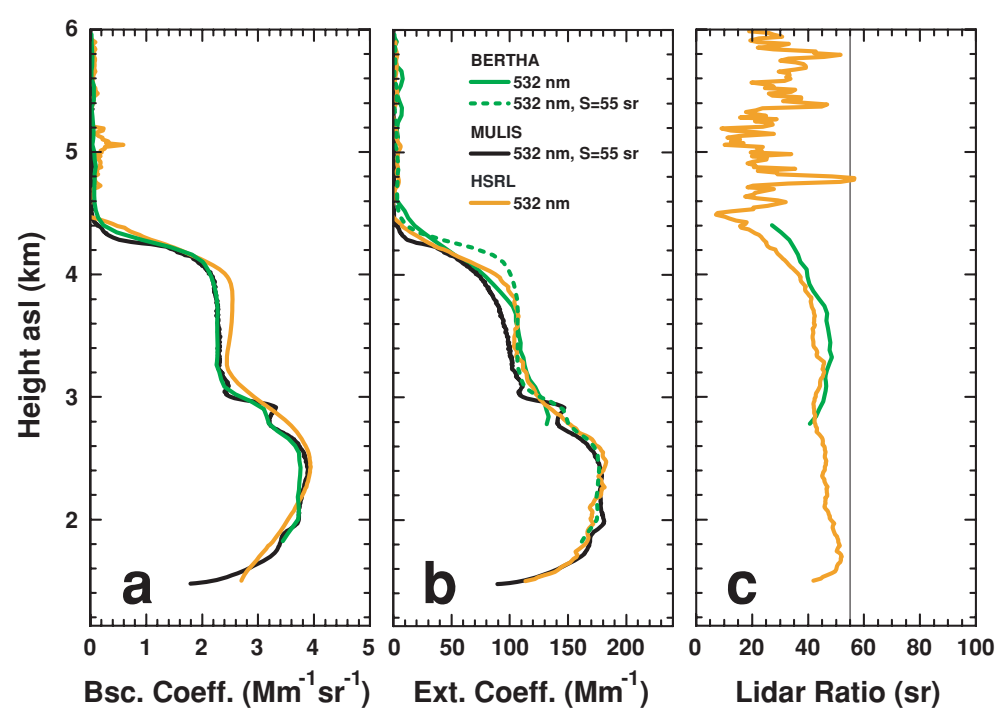

Fig. 10. Profiles of backscatter coefficient (a), extinction coefficient (b) and lidar ratio (c), determined from MULIS (black), BERTHA (green) and airborne HSRL observations (orange) on 3 June 2006. MULIS backscatter and extinction profiles are calculated with the Fernald method by assuming a lidar ratio of $55 \mathrm{sr}$. BERTHA observations are based on the Raman lidar method (solid lines). The dotted line (extinction down to $1.5 \mathrm{~km}$ height a.s.1.) is obtained by applying the Fernald method. BERTHA and MULIS observations show 0400-0500 UTC mean values. Signals recorded within $13 \mathrm{~s}$ around $0414 \mathrm{UTC}$ are averaged in the case of the HSRL.
Figure 10 shows the comparison of profiles of the backscatter and extinction coefficients and the lidar ratio derived from ground-based and airborne lidar data. The agreement is very good. The lidar ratio is $40-50 \mathrm{sr}$ in the upper layer and increases slighlty in the desert dust layer below. The profile of the volume depolarization ratio (shown in Fig. 3) is almost constant with height. The particle depolarization ratio is $30 \%-$ $32 \%$ throughout the plume at $532 \mathrm{~nm}$ (Freudenthaler et al., 2008).

3.1.3. 19 May 2006. This day of the first dust period was selected as one of the key days of SAMUM. Clear skies around 1100 UTC allowed optimum satellite observations of dust optical properties (Dinter et al., 2008; Kahn et al., 2008). Figure $11 \mathrm{~b}$ provides an overview of the dust layering from 1000-1250 UTC on that day. According to Fig. 5b, the dust was transported from central Algeria. The radiosonde indicates a dry dust layer with maximum values of the relative humidity of less than 50\% around 1045 UTC (radiosonde launch at 1038 UTC). The convective activity in the boundary layer after 1100 UTC destroys the stable aerosol layering that developed during nighttime. Clouds observed after 1200 UTC indicate that the convective updrafts reached the dust layer top. More details to the boundary layer evolution is given by Ansmann et al. (2008) and Knippertz et al. (2008).

Figure 11c compares the optical depths derived from groundbased lidars, airborne lidar and AERONET photometer observations. Good agreement between the different observations is found. The optical depth is almost constant with values around 0.4. The Ångström exponents shown in Fig. 4 are 0.1-0.2 (380$500 \mathrm{~nm})$ and $0.3-0.4(500-1020 \mathrm{~nm})$.

Figure 12 shows a large set of profiles of dust optical properties derived from the observations with the four lidars at multiple wavelengths. Different signal averaging periods (BERTHA, 0959-1116 UTC; POLIS, 1000-1116 UTC; MULIS, 1016-
1051 UTC; HSRL, 1108-1109 UTC) may explain the slight differences between the profiles for a given wavelength.

For this measurement example, the methods available for daytime lidar data analysis are briefly explained. For the determination of the backscatter coefficients at 355, 400, 800 and $1064 \mathrm{~nm}$ (BERTHA, POLIS), only elastic backscatter signals are available at daytime. In this case, the Fernald method must be applied to determine the profile of the backscatter coefficient. As input, a height-independent extinction-to-backscatter ratio is required. The used lidar ratio is indicated in Figs. 12a and b. The lidar ratio for the long wavelengths $(800,1064 \mathrm{~nm})$ is estimated to be about $10 \%$ higher than at 355 and $532 \mathrm{~nm}$ (see explanation in section 3.2.1, 15 May observation). From the particle backscatter coefficients several Ångström exponents are calculated.

At 532 nm, the Fernald method (MULIS, BERTHA), the rotational Raman lidar method (BERTHA) and the HSRL method (airborne HSRL) are available to calculate backscatter coefficient profiles. The agreement between the different solutions in Fig. 12a is good when keeping the different signal averaging times as mentioned above into account.

The extinction values in Fig. $12 \mathrm{~b}$ are either directly determined (BERTHA, rotational Raman lidar method, HSRL method) or computed from the backscatter coefficient profiles by simply multiplying the backscatter values with the lidar ratio used in the Fernald backscatter retrieval. The vertical integrals of the extinction coefficients yield the optical depths that are shown in Fig. 11c.

The lidar ratio profiles in Fig. 12c are calculated by applying the Raman lidar method and the HSRL method. The HSRLderived lidar ratio clearly shows that the assumption of a heightindependent lidar ratio in the Fernald method is justified on this day. The rather narrow RFOV of the rotational Raman channels of BERTHA prohibit a trustworthy application of the Raman lidar retrieval technique at heights $<3.5 \mathrm{~km}$ a.s.l. A very good 


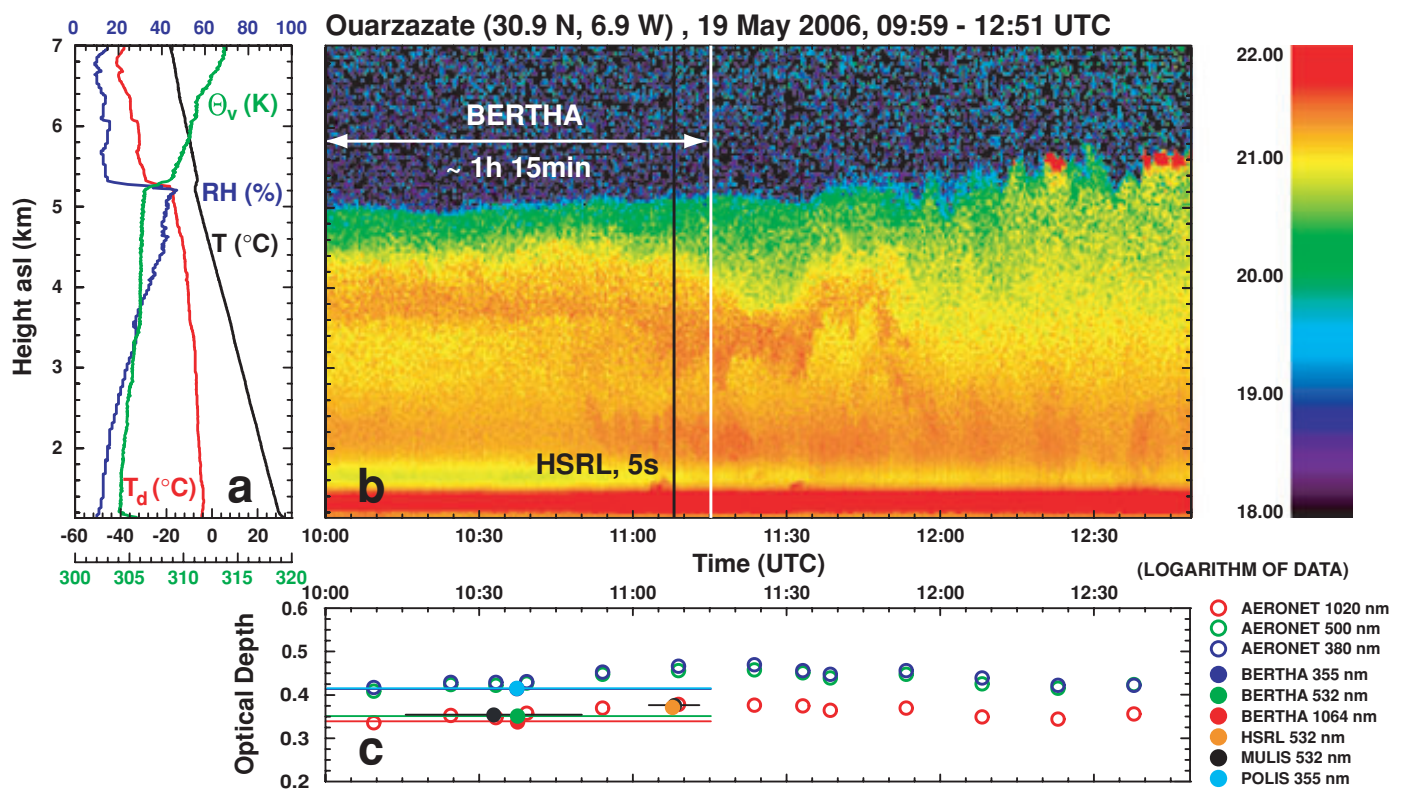

Fig. 11. Saharan dust layer observed with (a) radiosonde (launch at 1038 UTC) and (b) BERTHA (range-corrected $532 \mathrm{~nm} \mathrm{signal,} 60 \mathrm{~m}, 30 \mathrm{~s}$ resolution) on 19 May 2006, 0959-1251 UTC. FALCON overflight on 19 May 2006, was at 1108 UTC (vertical black line). Sun photometer observations (open circles) and lidar observations (closed circles) of the optical depth for several wavelengths are presented in (c). Lengths of the horizontal bars in (c) indicate the MULIS, POLIS and BERTHA signal averaging periods (see indicated time period in $b$ for BERTHA).

Ground-based lidar values of the dust optical depth are computed from backscatter-coefficient profiles by assuming a lidar ratio of 55 sr. A 5 -second average value of the optical depth from the HSRL measurement is also shown (orange circle).
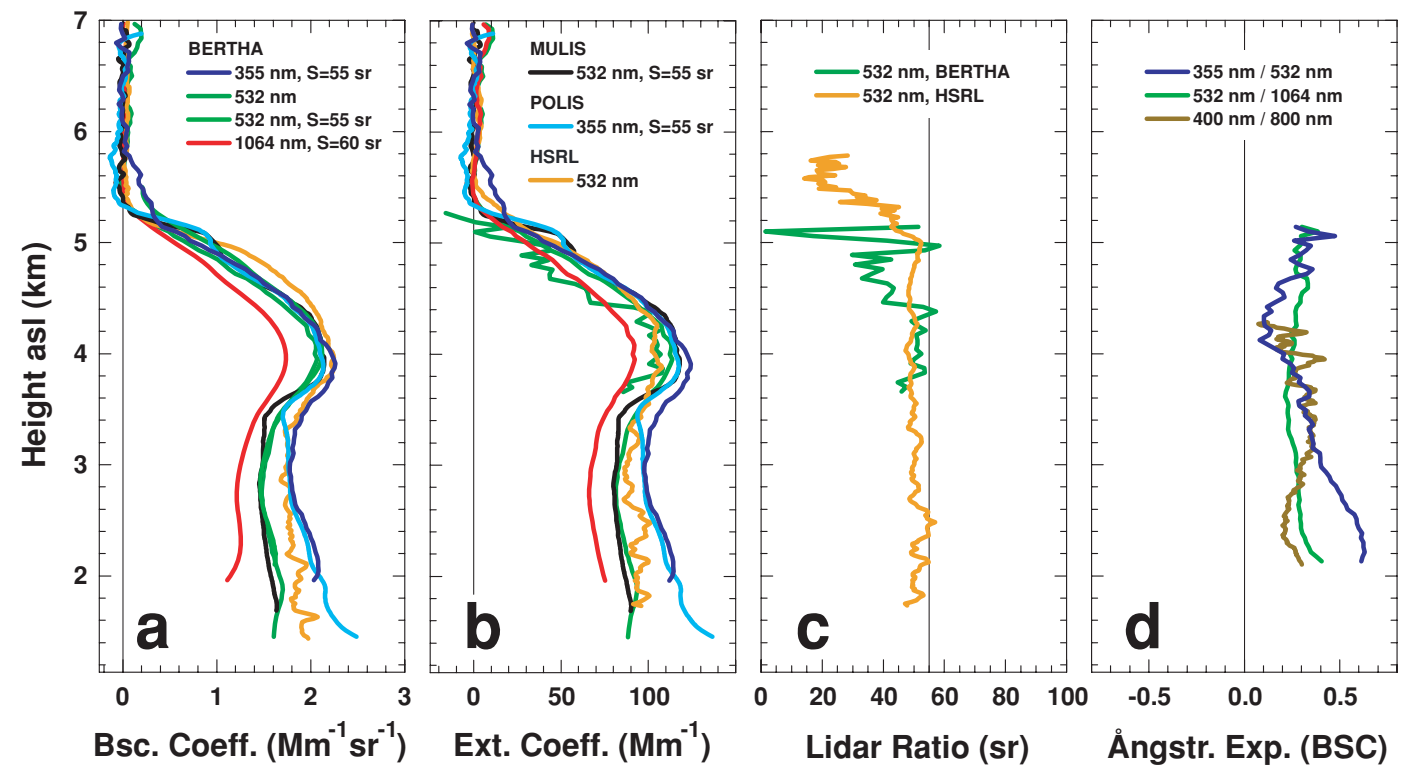

Fig. 12. Daytime measurement of dust optical properties with BERTHA (green, blue, red, brown), MULIS (black), POLIS (cyan) and airborne HSRL (orange) on 19 May 2006, around 1100 UTC. Backscatter coefficients (a) and extinction coefficients (b) at three wavelengths, the $532 \mathrm{~nm}$ lidar ratio (c, BERTHA, HSRL), and the backscatter-related Ångström exponent (d, BERTHA) for the wavelengths pairs $355 \mathrm{~nm} / 532 \mathrm{~nm}$, $400 \mathrm{~nm} / 800 \mathrm{~nm}$ and $532 \mathrm{~nm} / 1064 \mathrm{~nm}$ are shown. The Fernald method is used when the lidar ratio of $55 \mathrm{sr}(355,532 \mathrm{~nm})$ and $60 \mathrm{sr}(1064 \mathrm{~nm})$ is given as a number. In addition, rotational Raman signals (BERTHA) could be used to compute backscatter, extinction and lidar ratio values (dark green). Mean profiles (BERTHA, POLIS, 75 min; MULIS, 35 min; HSRL, 14 s) are shown. Signal smoothing lengths range from 300-660 m. 


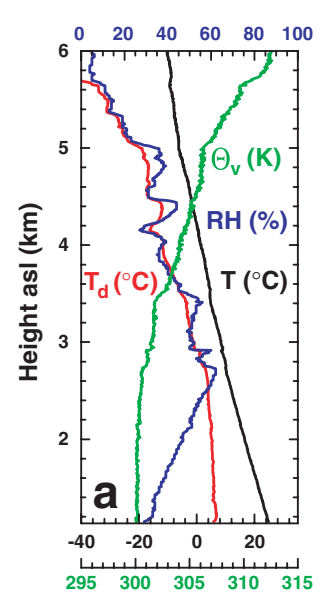

Ouarzazate $(30.9 \mathrm{~N}, 6.9 \mathrm{~W}), 4$ June 2006, 09:24 - 12:25 UTC
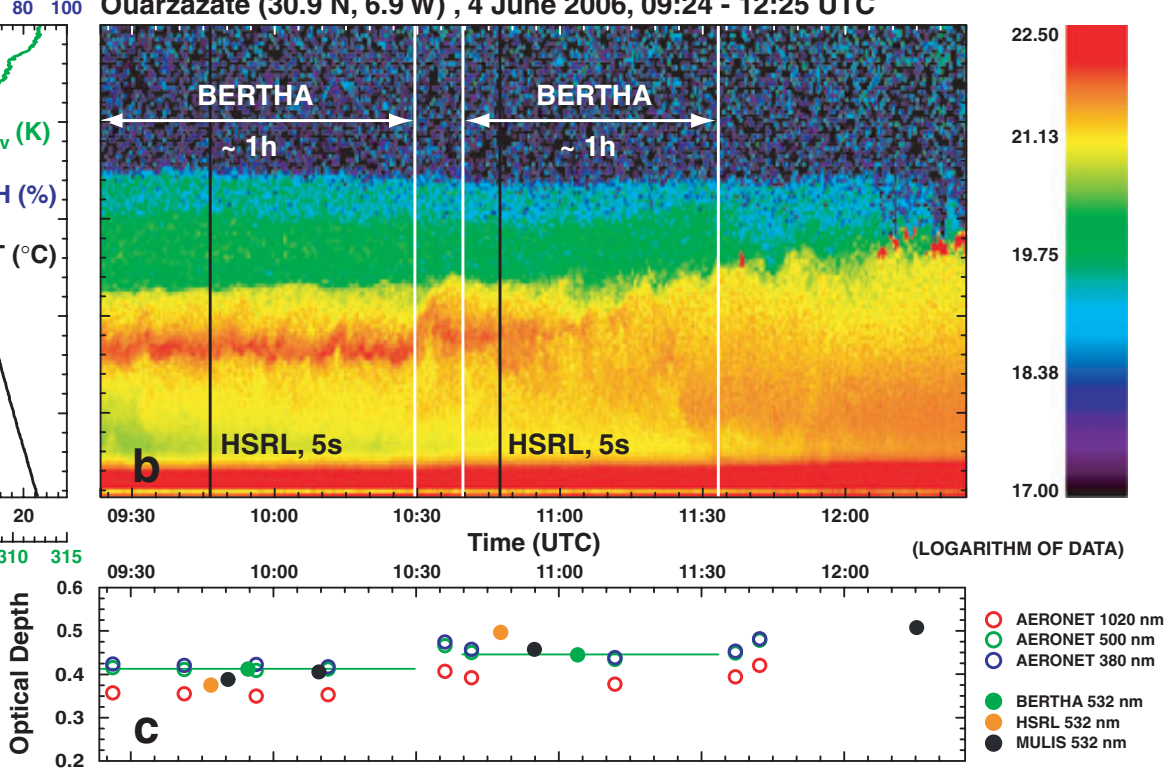

Fig. 13. Same as Fig. 11 except for 4 June 2006, 0924-1225 UTC. The FALCON overflights on 4 June 2006, were at 0948 and 1047 UTC (vertical black lines). Radiosonde was launched at 1039 UTC (a). Sun photometer observations (open circles) and lidar observations (closed circles, BERTHA, about 1-h averages, MULIS, $5 \mathrm{~min}$; HSRL, $5 \mathrm{~s}$ ) of the optical depth for several wavelengths are presented in (c). Lengths of the horizontal bars in (c) indicate the BERTHA signal averaging periods (same as in b, white lines). Lidar values are computed from backscatter-coefficient profiles by assuming a lidar ratio of $55 \mathrm{sr}$. Two 5 -second average values derived from the HSRL measurement (orange) are shown in addition.

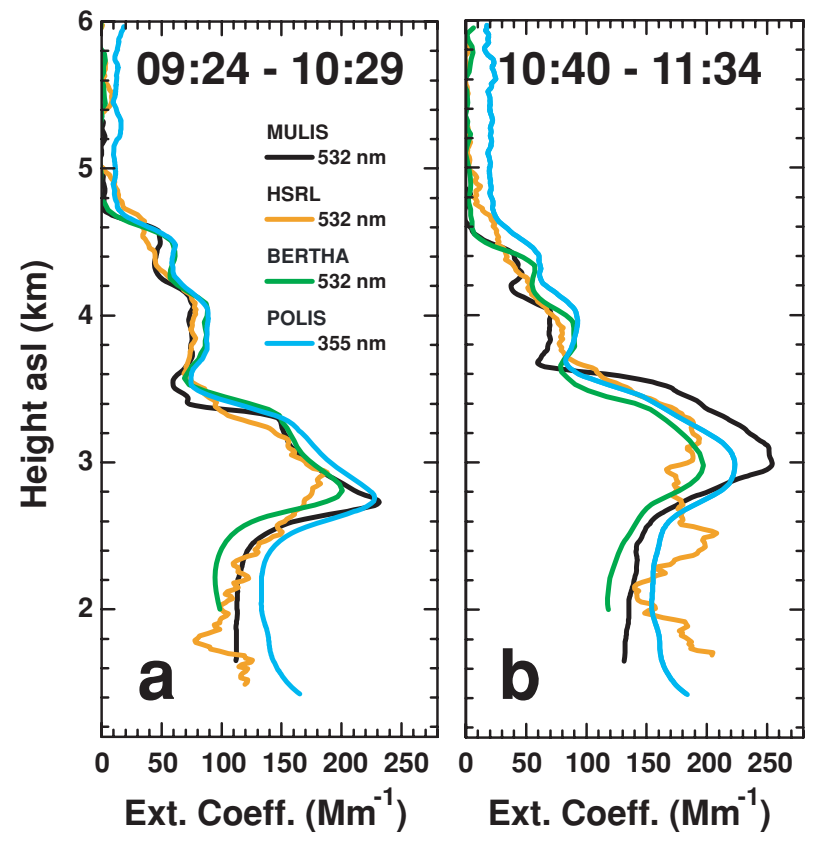

Fig. 14. Daytime measurement of dust extinction coefficients on 4 June 2006, 0924-1029 UTC and 1040-1134 UTC (BERTHA, averaging periods). Ground-based lidar data are computed from the elastic backscatter signals (Fernald method, lidar ratio of $55 \mathrm{sr}$ ). Airborne lidar data are analysed by applying the HSRL method. Different signal averaging periods (see text) are used for the different lidars. Signal smoothing lengths are 150-300 m. agreement is found for the lidar ratio. Noise determines the Raman-lidar solution above $4.5 \mathrm{~km}$ height.

3.1.4. 4 June 2006. Two more FALCON overflights took place on 4 June 2006, at 0948 UTC and 1047 UTC, respectively. According to Fig. 5d the air flow from Algeria was re-established on the late morning of 4 June when several satellites overpassed the SAMUM area (Kahn et al., 2008). However, only in the layer above $3.5 \mathrm{~km}$ height a.s.l. air was clearly advected from easterly directions (Esselborn et al., 2008). Figure $13 \mathrm{~b}$ shows the range-corrected signal of the $532 \mathrm{~nm}$ channel for the time period from 0924-1225 UTC. Black lines in the figure denote the overpasses of the research aircraft, white lines mark the time intervals that were used for signal averaging (BERTHA). Figure 13c shows the optical depth from the Sun photometer (380, 500 and $1020 \mathrm{~nm}$, open circles) and the lidar measurements.

According to Figure 13b, a dust plume up to a height of $4.5 \mathrm{~km}$ a.s.l. is present. In the middle of the plume, a layer of higher concentration (stronger signals) and higher relative humidity is visible. In the first $70 \mathrm{~min}$ of the measurement (before 1030 UTC), the structure of this layer and of the whole plume does not change much. The stable stratification that formed during nighttime dissolves and subsequently the dust is mixed down to lower heights when the strong convective motions in the developing boundary layer reach $2.5-3 \mathrm{~km}$ height a.s.l. after 1030 UTC. Again, clouds appear after 1200 UTC at the top of updraft plumes. 

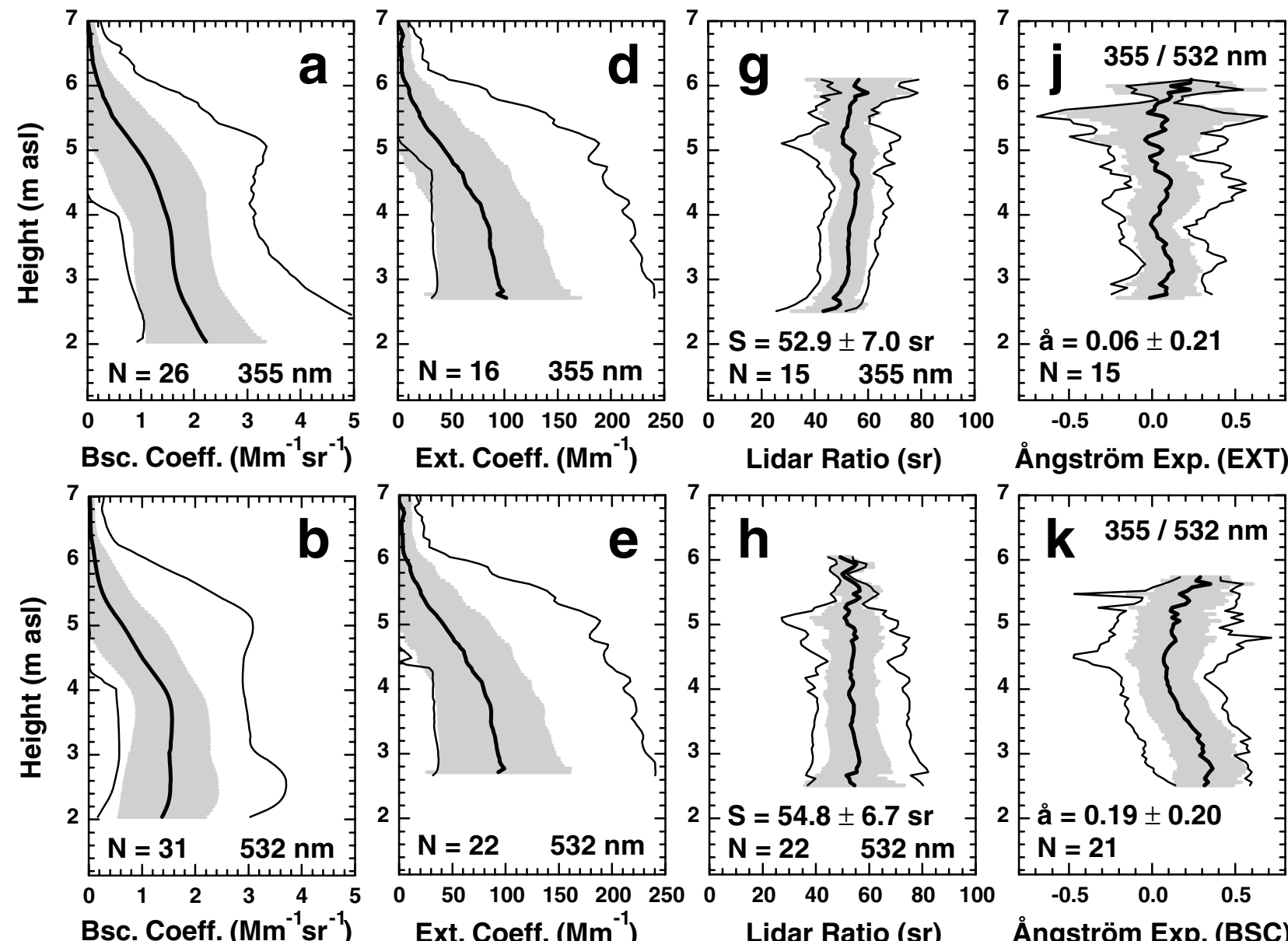

Ext. Coeff. $\left(\mathrm{Mm}^{-1}\right)$

Lidar Ratio (sr)
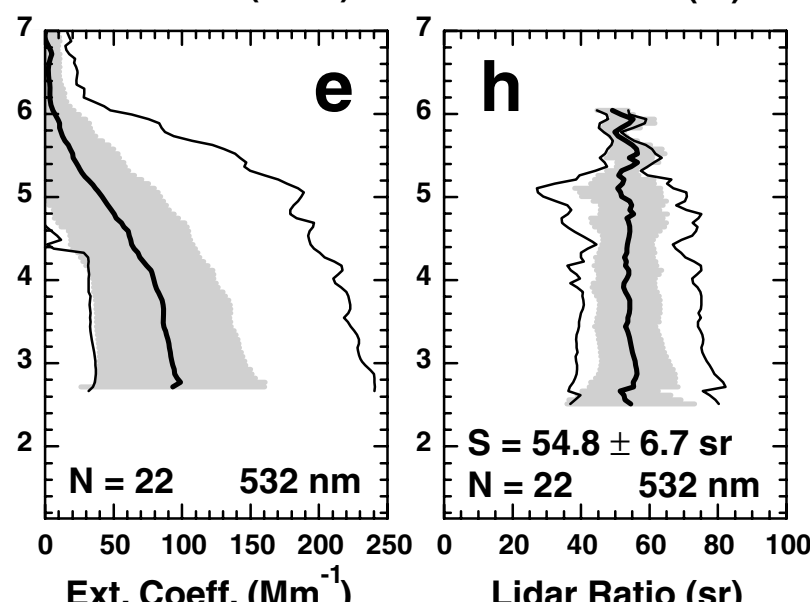

Ångström Exp. (EXT)
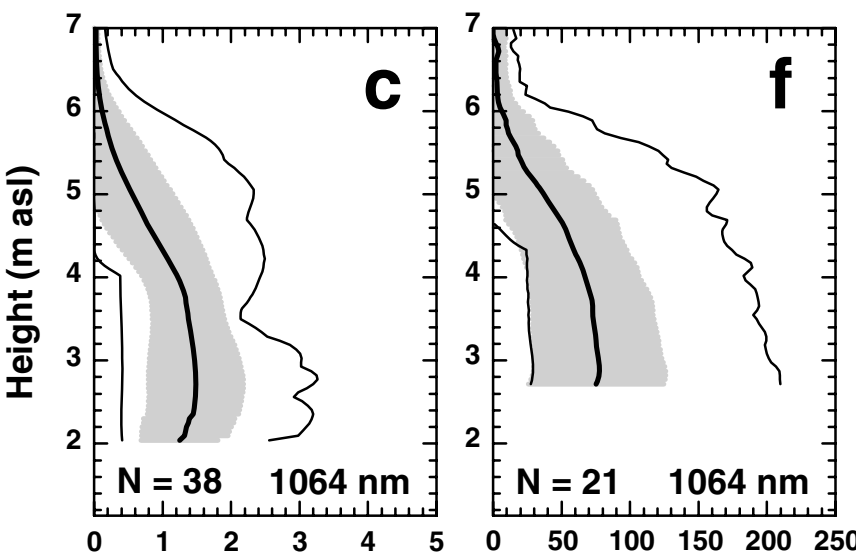

Lidar Ratio (sr)

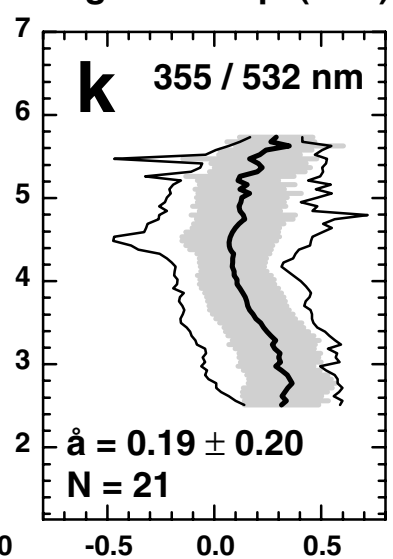

Bsc. Coeff. $\left(\mathrm{Mm}^{-1} \mathrm{sr}^{-1}\right)$ Ext. Coeff. $\left(\mathrm{Mm}^{-1}\right)$

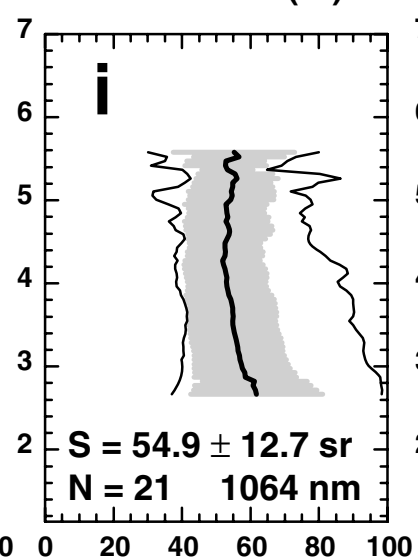

Lidar Ratio (sr)
Ångström Exp. (BSC)

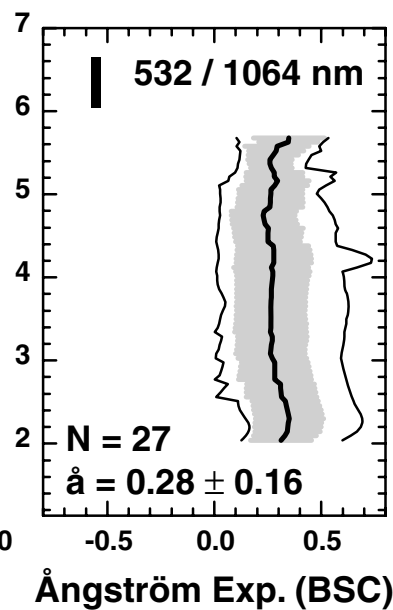

Fig. 15. Mean profiles (thick black lines) and standard deviations (grey areas) of the backscatter coefficient (a-c), the extinction coefficient (d-f) and the lidar ratio (g-i) at 355, 532 and $1064 \mathrm{~nm}$, and of extinction- (j) and backscatter-related Ångström exponents (k,l). The thin lines show the range of observed values (minimum to maximum value) for each height bin. $N$ denotes the number of averaged profiles. The mean values of the mean profiles (thick lines) are given as numbers for the lidar ratio $S$ and the Ångström exponent $a$. The given values of mean standard deviation are calculated from the grey areas, that is, they are the mean values of the standard-deviation height profiles.

Figure 14 shows extinction profiles derived from all four lidar observations. A very good agreement is also found in this case. Differences are again mainly due to different signal averaging periods (BERTHA, 0924-1029 UTC and 1040-1134 UTC as indicated in the figure; POLIS, 0924-1026 UTC and 1030-1125 UTC; MULIS, 0951-1010 and 1055-1215; HSRL, 0948 and 1047 UTC, about $5 \mathrm{~s}$ each). High extinction coefficients in the lofted plume (2.5-3.5 km height a.s.1.) of more than $200 \mathrm{Mm}^{-1}$ 
are found. The FALCON HSRL measured lidar ratios of 45$48 \mathrm{sr}$ ( $<2.4 \mathrm{~km}$ height a.s.1.), 40-45 sr (2.4-3.5 km height a.s.1.), and $48-50 \mathrm{sr}$ in the upper layer that was identified as pure dust layer (Esselborn et al., 2008).

\subsection{Statistical results}

Saharan dust was present over Ouarzazate on more than 20 days during the four-week campaign. 53 morning and evening lidar measurements, lasting from $30 \mathrm{~min}$ to several hours, were performed. The average profiles (four-week means) for a variety of parameters, the corresponding standard deviations and extreme values for each height bin are shown in Fig. 15. BERTHA observations are considered only. The number $N$ of individual profiles, considered in the averaging, varies for the different parameters because of the following reasons. Day- and nighttime profiles of backscatter coefficients are available (Figs. 15a-c), but only nighttime profiles of the extinction coefficient are included in Figures $15 \mathrm{~d}$ and e. To better compare 355 and $532 \mathrm{~nm}$ extinction values, rotational Raman lidar measurements are excluded here. A few of the determined backscatter and extinction profiles showed a strong impact of the remaining laser-beam RFOV overlap effect (after correction), so that only the uppermost part of the height profile within the dust layer was useful as comparisons with the observations of the other two lidars indicated. These profiles were removed from the data set.

The lidar ratio for the wavelength of $1064 \mathrm{~nm}$ is obtained in the following way. In the first step, the particle backscattercoefficient profile at $1064 \mathrm{~nm}$ is computed. In the second step, the profile of the $1064 \mathrm{~nm}$ extinction coefficient is estimated from the respective profile of the $532 \mathrm{~nm}$ extinction coefficient by assuming a height-independent 532/1064 nm Ångström exponent. This Ångström exponent was assumed to be equal to the 500/1020 nm Ångström exponent that was measured shortly before sunset with the AERONET Sun photometer (see Fig. 4). The individual profile of the $1064 \mathrm{~nm}$ lidar ratio is then obtained from the $1064 \mathrm{~nm}$ backscatter and extinction coefficients in the third and final step. In Figs. 15f and i, we included only observations for which almost constant dust conditions in the late afternoon and early evening were given. This procedure provides trustworthy profiles of the $1064 \mathrm{~nm}$ lidar ratio as long as the assumption of a height-invariant 532/1064 nm Ångström exponent is fulfilled. The lidar-derived $355 / 532 \mathrm{~nm}$ Ångström exponent always showed an almost height-independent behaviour in the dust plumes so that a similar behaviour can be expected for the 532/1064 nm Ångström exponent.

The individual profiles of the three different Ångström exponents are directly calculated from the respective lidar profiles of the extinction $(355,532 \mathrm{~nm})$ and backscatter coefficients $(355$, $532,1064 \mathrm{~nm})$. Only simultaneous observations can be considered (Figs. 15j-1).

Comparably constant extinction and backscattering properties were found in the lowermost $3 \mathrm{~km}$ of the atmosphere. The decrease of the backscatter and extinction values between 4$7 \mathrm{~km}$ height a.s.l. is attributed to the varying dust layer depth. Extinction coefficients were on average $100 \pm 50 \mathrm{Mm}^{-1}$ at 355 and $532 \mathrm{~nm}$ in the lowest $3 \mathrm{~km}$ above ground and ranged from $30 \mathrm{Mm}^{-1}$ on clear days to almost $300 \mathrm{Mm}^{-1}$ during days with high dust burden (14 May). Somewhat lower values are obtained at $1064 \mathrm{~nm}$.

In contrast to the extensive quantities, the intensive quantities (lidar ratio, Ångström exponent) vary only weakly with height. This corroborates that the dust plumes (observed in the early evening) were well-mixed. A wavelength dependence of the lidar ratio is not found. The dust lidar ratios are, on average, $53-55 \mathrm{sr}$ at all three laser wavelengths. The standard deviation is small with values around $7 \mathrm{sr}(355$ and $532 \mathrm{~nm})$. The profile of maximum $1064 \mathrm{~nm}$ lidar ratios shows values up to 80-100 sr and the corresponding standard deviation of $13 \mathrm{sr}$ is comparably large. These high values may indicate that the assumption of constant dust properties from the late afternoon to the early evening was not always valid.

If we only consider the observations taken during the first well-defined dust period from 13 to 22 May 2006, the mean lidar ratio is $55 \pm 5 \mathrm{sr}(355 \mathrm{~nm}), 56 \pm 5 \mathrm{sr}(532 \mathrm{~nm})$ and $59 \pm$ $7 \mathrm{sr}(1064 \mathrm{~nm})$. The FALCON lidar measured lidar ratios from $38-55$ sr. By considering only cases for which the backward trajectories indicate the advection from desert regions, the lidar ratio is $50 \pm 4 \mathrm{sr}$ (Esselborn et al., 2008). The FALCON flights were done in the final phase of the first dust period on 19 and 20 May, on 28 May and during the second dust period on 3 and 4 June.

The mean extinction-related Ångström exponent in Fig. 15j is almost zero, whereas the backscatter-related Ångström exponents show, on average, positive values around $0.2-0.3$. The scatter in the data (see minimum-maximum range) is caused by atmospheric variability and uncertainties in the data analysis.

Figure 16 shows histograms of the lidar ratios as measured with BERTHA on about 20 different days. This figure considers all determined values, even for small height profile sections $(<1000 \mathrm{~m})$. In contrast, Fig. 15 considers full profiles only. In the case of $532 \mathrm{~nm}$, vibrational Raman signals (81 nighttime values) as well as rotational Raman signals (additional 26 daytime observations) are analysed. Mean values for each $500 \mathrm{~m}$ thick vertical layer are included in the statistics. Again, a wavelengthindependent behaviour of the lidar ratio is found. More than $80 \%$ of the $355 \mathrm{~nm}$ lidar ratios and about $70 \%$ of the $532 \mathrm{~nm}$ lidar ratios are in the range from 45-60 sr.

The statistics of the dust layer top height are presented in Fig. 17. In addition, the dust-layer mean extinction coefficient at $500 \mathrm{~nm}$ is shown. The latter quantity is the ratio of the optical depth measured with Sun photometer to the dust layer height, simultaneously measured with BERTHA. 25 cases are analysed. On average, the dust layer depth is $3.8 \pm 0.8 \mathrm{~km}$. Most of the dust-layer mean extinction coefficients (75\% out of all cases) range from 80 to $120 \mathrm{Mm}^{-1}$, which is in good agreement with 

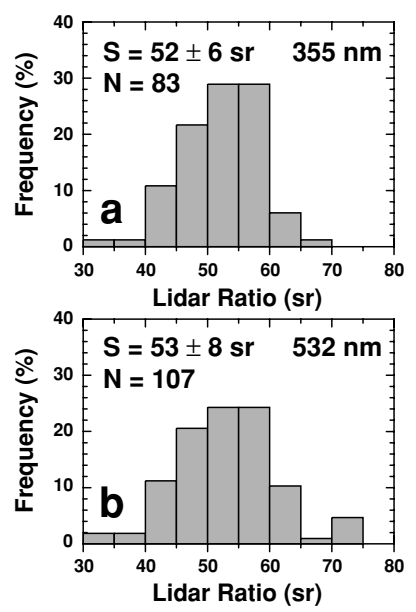

Fig. 16. Frequency distributions of dust lidar ratios at (a) $355 \mathrm{~nm}$ (based on 83 individual values of $500 \mathrm{~m}$ thick layers) and (b) $532 \mathrm{~nm}$ (based on 107 data points, for $500 \mathrm{~m}$ thick layers).
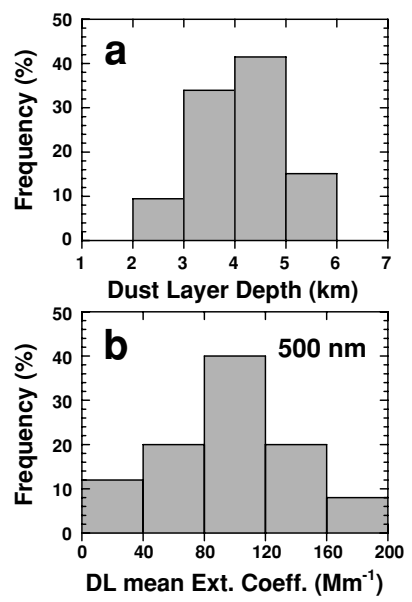

Fig. 17. Frequency distribution of (a) dust layer depth (from 53 morning and evening BERTHA observations) and (b) of dust layer mean extinction coefficient at $500 \mathrm{~nm}$ (from 25 simultaneous lidar photometer observations). The latter quantity is obtained by dividing the optical depth measured with the Sun photometer by the observed dust layer depth.

the lidar-derived mean profiles in Figs. 15d and e. Mean value is $95 \pm 40 \mathrm{Mm}^{-1}$ in Fig. $17 \mathrm{~b}$.

The histograms of the Ångström exponents derived from the AERONET photometer observations for the wavelength pairs of 380 and $500 \mathrm{~nm}$ and for 500 and $1020 \mathrm{~nm}$ are shown in Fig. 18. Only few days showed values larger than 0.6. Thus, most of the time pure dust conditions with little urban influence prevailed. The photometer-derived Ångström exponents for the $380-500 \mathrm{~nm}$ range are at all positive. The mean values are $0.28 \pm 0.29(380-500 \mathrm{~nm})$ and $0.36 \pm 0.26(500-1020 \mathrm{~nm})$. The difference between the mean 380/500-nm Ångström exponent and the lidar-derived value (extinction-related value is about zero for the 355/532-nm spectral range) may be caused by the fact that the photometer provides column-integrated values that
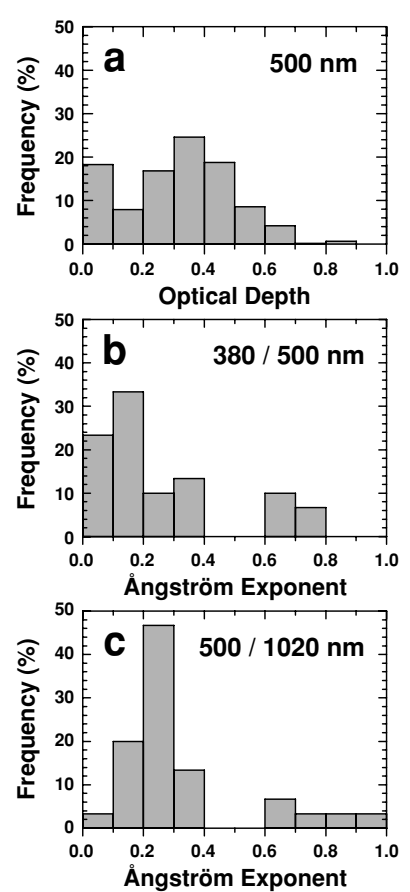

Fig. 18. Frequency distribution of (a) particle optical depth at $500 \mathrm{~nm}$, and Ångström exponents calculated from the optical depths at the wavelengths of (b) 380 and $500 \mathrm{~nm}$ and (c) 500 and $1020 \mathrm{~nm}$

(AERONET, level 2.0 data). Ångström exponents smaller than 0.4 correspond to mineral dust whereas the ones larger than 0.6 are caused by mixtures of dust and anthropogenic aerosol during situations with low optical depth $(<0.2)$. Mean optical depth is 0.32 at $500 \mathrm{~nm}$ for the one-month time period.

are influenced by surface-near aerosols, whereas the lidar values describe the aerosol properties above $3 \mathrm{~km}$ height a.s.l. only. A minor effect of anthropogenic pollution may be responsible for the higher Angström exponents derived from the photometer observations. In the spectral range $>500 \mathrm{~nm}$ the influence of submicron urban particles is much lower so that the agreement between photometer- and lidar-derived Ångström exponents is better here.

Another important product of the SAMUM lidar observations is the depolarization ratio and its wavelength dependence. These observations are presented by Freudenthaler et al. (2008) and Esselborn et al. (2008). The SAMUM-mean particle depolarization ratio for desert dust is $0.31 \pm 0.03$ and $0.27 \pm 0.04$ at 532 and $1064 \mathrm{~nm}$, respectively. Measurements at $355 \mathrm{~nm}$ suggest a slighly lower value for the UV wavelength compared with the $532 \mathrm{~nm}$ values, the same seems to be the case for $710 \mathrm{~nm}$.

\subsection{Discussion on lidar ratio}

The volume backscatter coefficient of dust particles and the lidar ratio are very sensitive to changes in the shape characteristics of the dust particles (Mishchenko et al., 1997; Barnaba and Gobbi, 2001; Liu et al., 2002; Mattis et al., 2002c). The SAMUM observations reveal that the lidar ratio of dust (close to the Saharan 
source region) is around $55 \mathrm{sr}$ at the three laser wavelengths of 355,532 and $1064 \mathrm{~nm}$. A wavelength dependence is not found. For the first time, a thorough test of dust models that are used to compute the dust optical properties as a function of size distribution, particle morphology and chemical composition (index of refraction) can be performed (see Wiegner et al., 2008). Discrepancies between SAMUM observations and model results cannot be related to the possible influence of long-range transport, that is, of mixing, transformation and removal processes, which often make comparisons difficult. In the study of Wiegner et al. (2008), the model produces a pronounced decrease of the lidar ratio with wavelength. Lidar ratios are larger by a factor of about 2 at $355 \mathrm{~nm}$ than at $532 \mathrm{~nm}$ and lower by a factor of about 1.5 at $1064 \mathrm{~nm}$ than at $532 \mathrm{~nm}$. As will be discussed in a forthcoming paper by Müller et al., the improved AERONET retrieval algorithm (new version of the dust model) allows for a much better estimation of the dust extinction-to-backscatter ratio, compared with an older study of Saharan dust (Müller et al., 2003), when the model presented in Dubovik et al. (2002) was applied. For several AERONET observations on 19 May 2006, between 0630-0830 UTC, the calculations yield lidar ratios of 70-80 $(440 \mathrm{~nm}), 70-75(500 \mathrm{~nm})$ and 55-70 $\mathrm{sr}$ (for the wavelengths of 670, 870 and $1020 \mathrm{~nm}$ ).

Many Raman lidar observations of desert-dust lidar ratios became available during the last 6 years. Measurements in Saharan dust are discussed by Mattis et al. (2002c), Müller et al. (2003), Ansmann et al. (2003), De Tomasi et al. (2003), Balis et al. (2004), Amiridis et al. (2005), Mona et al. (2006), Müller et al. (2007) and Papayannis et al. (2008). Lidar ratios measured in Asian dust are reported by Liu et al. (2002), Sakai et al. (2002), Murayama et al. (2003, 2004), Noh et al. (2007), Tesche et al. (2007) and Chen et al. (2007).

Mattis et al. (2002c) were the first who presented observations of the wavelength dependence of the dust lidar ratio (355 to $532 \mathrm{~nm}$ ). These observations were taken in lofted (isolated) dust plumes of two major Saharan dust outbreaks that reached northern Europe. Extinction coefficients were as high as $200-270 \mathrm{Mm}^{-1}$ over Leipzig, Germany, in October 2001. The 355/532-nm extinction-related Ångström exponents were zero and the lidar ratios were around $75 \mathrm{sr}$ at both wavelengths of 355 and $532 \mathrm{~nm}$ in the main dust layer. During another outbreak in August 2001, lidar ratios were slightly lower with values around $70 \mathrm{sr}$ at $355 \mathrm{~nm}$ and $50-70 \mathrm{sr}$ at $532 \mathrm{~nm}$ in layers between 3 and $8 \mathrm{~km}$ height. Long-range transport over 3000-5000 km may have led to the removal of the large silt-sized particles and, as a result, to higher lidar ratios than found during SAMUM.

De Tomasi et al. (2003) observed lidar-ratio profiles over Lecce in southern Italy during three heavy dust outbreaks from the western Saharan region. The lidar ratio varied around 51, 53 and $57 \mathrm{sr}$ at $351 \mathrm{~nm}$. Amiridis et al. (2005) analysed 4 years of lidar observations at Thessaloniki, Greece, and found an average lidar ratios of $57 \pm 29 \mathrm{sr}$ at $355 \mathrm{~nm}$ for the Saharan-dust backward trajectory cluster. The large standard deviation mainly expresses the atmospheric variability caused by mixing of dust with maritime and anthropogenic particles during the long-range transport.

Berthier et al. (2006) combined profiles of the particle backscatter coefficients derived from spaceborne Lidar-in-space Technology Experiment (LITE, September 1994) observations with optical depths derived from METEOSAT-5 observations of dust outbreaks over the tropical North Atlantic west of Africa. They retrieved layer-integrated (column) dust lidar ratios of $57 \pm 27 \mathrm{sr}$ at $532 \mathrm{~nm}$. Here, the standard deviation may express to a large part the uncertainty in the retrieval.

Léon et al. (2003) and Kaufman et al. (2003) combined aircraft lidar observations of particle backscatter-coefficient profiles and particle optical depths derived from Moderate Resolution Imaging Spectroradiometer (MODIS) data. These observations were done a few hundreds of kilometres west of Africa over the Atlantic Ocean during the Saharan Dust Experiment (SHADE, Tanré et al., 2003). Kaufman et al. (2003) derived a column lidar ratio of $63 \mathrm{sr}$ for both wavelengths (530 and $1060 \mathrm{~nm}$ ) during a heavy dust outbreak with an optical depth of 0.9. From the results presented by Léon et al. (2003), it can be concluded that the column lidar ratio was close to 56 sr during a case with a dust optical depth of 0.8 .

Dust measurements in southern Europe (Italy, Greece) often show values around $40 \mathrm{sr}$ at $351-355 \mathrm{~nm}$ (Balis et al., 2004; Mona et al., 2006). Mixing with maritime particles (causing a lidar ratio of around 20-25 sr; Ansmann et al., 2002b; Franke et al., 2003) is assumed to be mainly responsible for this effect (Papayannis et al., 2008). The Ångström exponents, derived from the 355- and 532-nm backscatter coefficients, ranged mostly from $0.5-1$ and therefore suggest a mixture of dust and non-dust particles (maritime and urban aerosols).

A similar behaviour of the lidar ratio in aged dust layers is also found in eastern Asia. Because of mixing with pollution (mainly causing lidar ratios $<45 \mathrm{sr}$; Tesche et al., 2007) and maritime particles, lidar ratios are typically $<50 \mathrm{sr}$ in dust layers identified by backward trajectories (Sakai et al., 2002; Murayama et al., 2003; Chen et al., 2007; Noh et al., 2007). Sakai et al. (2002) present a case measured over Japan with an increasing Ångström exponent (from 0 to 1 ) and relative humidity (from $20 \%$ to $60 \%$ ) within a lofted layer assigned as dust layer according to backward trajectories and hypothesized that such cases indicate a mixture of dust with sulfate particles. Murayama et al. (2003) observed another interesting case over Japan with complex layering and mixing. Below about $3.5 \mathrm{~km}$ height, the Ångström exponent decreased from $1.5-2$ below $2 \mathrm{~km}$ height to $0.3-1$ at $3-3.5 \mathrm{~km}$ height. Only in the uppermost layer above $3.5 \mathrm{~km}$ a clear dust signature with Ångström values of $0-0.5$, particle depolarization ratios of $30 \%-35 \%$ and lidar ratios from $45-60 \mathrm{sr}$ at $532 \mathrm{~nm}$ were found.

Murayama et al. (2004) performed first simultaneous lidar observations at 355 and $532 \mathrm{~nm}$ in Asian dust over Japan. Similar 
lidar ratios around $50 \mathrm{sr}$ at both wavelengths in a lofted, isolated dust layer were found. Noh et al. (2007) present another lidar ratio study in South Korea with values simultaneously measured at 355 and $532 \mathrm{~nm}$ and found lidar ratios between 50 and $60 \mathrm{sr}$ at both wavelengths in a layer with an enhanced volume depolarization ratio (close to $25 \%$ ).

Recently Liu et al. (2008) presented spaceborne CALIPSO lidar observations of long-range transport of Saharan dust from Africa to the United States of America in August 2006. CALIPSO data were analysed by using the dust optical depth derived from MODIS as a constraint. In a second approach, the two-wavelengths CALIPSO lidar observations were analysed by assuming the backscatter-related 532/1064-nm Ångström exponent to be constant throughout the entire dust layer. From the spaceborne lidar data, column lidar ratios of $41 \pm 5 \mathrm{sr}$ at $532 \mathrm{~nm}$ and $52-55 \pm 10 \mathrm{sr}$ at $1064 \mathrm{~nm}$ for optically thick desert dust plumes are retrieved. The CALIPSO results are not corrected for multiple-scattering effects, which can cause a significant underestimation of the particle optical depth and the related column lidar ratio (Young et al., 2006) in any case of weak, moderate or strong extinction of light by the dust particles (Wandinger, 1998). The influence of multiple scattering on ground-based lidar observations of desert dust is negligible (Ackermann et al., 1999). Furthermore, Ansmann (2006) shows that a significant underestimation of the column lidar ratio can occur when a twolayer system, with mostly maritime particles below $1 \mathrm{~km}$ height and dust particles above $1 \mathrm{~km}$ height, is observed from space. The effect is small if the lidar ratios for maritime and dust particles are not very different, as is the case for $1064 \mathrm{~nm}$ (but not for $532 \mathrm{~nm})$.

These error sources may explain the large $(532 \mathrm{~nm})$ and small $(1064 \mathrm{~nm})$ discrepancies between the SAMUM lidar ratios and the CALIPSO results. Finally, it should be noted that we observed again dust lidar ratios clearly above $50 \mathrm{sr}$ in most observations at Cape Verde in the Atlantic Ocean, about $500 \mathrm{~km}$ west of the African continent, during the second phase of SAMUM in the winter and summer seasons of 2008.

\section{Summary}

We presented profile observations of the optical properties of pure desert dust with advanced aerosol lidars. Such observations have never been done before and seem to be only possible at sites in or very close to a desert. Three ground-based Raman lidars and an airborne HSRL were used for the first time in a large dust field campaign. Observations with an AERONET Sun photometer equipped with a $1640 \mathrm{~nm}$ channel and radiosounding of meteorological parameters complemented the ground-based activities at Ouarzazate airport. The lidars measured height profiles of the volume backscatter and extinction coefficients at several wavelengths, the extinction-to-backscatter ratio at two wavelengths and the corresponding backscatter- and extinctionrelated Ångström exponents. The lidars thus provided key experimental data to test parametrizations of light scattering by dust, of radiative transfer codes and inversion schemes used to estimate microphysical properties from multiwavelength photometer observations. Lidar ratios for pure dust are also needed to estimate the vertical profile of the particle extinction coefficient and the dust optical depth from observations with standard backscatter lidars such as the spaceborne CALIPSO lidar.

Four case studies were presented. Two case studies dealt with the comparison of observations of the three ground-based lidars during a heavy dust outbreak and of the ground-based lidars with the airborne lidar. Very good agreement between the different measurements were found. Two further cases (SAMUM key days) showed profile observations during satellite overpasses on 19 May and 4 June, 2006.

The height resolved statistical analysis revealed that the dust layer depth typically reaches $4-6 \mathrm{~km}$ height a.s.l., sometimes even $7 \mathrm{~km}$. A vertically inhomogeneous dust plume with internal dust layers was usually observed in the morning, before the evolution of the convective boundary layer. The Saharan dust layer was well mixed in the early evening. The $500 \mathrm{~nm}$ dust optical depth ranged from 0.2-0.8 at Ouarzazate, Ångström exponents derived from photometer and lidar data were mainly between $0-0.4$. The volume extinction coefficients varied from $30-300 \mathrm{Mm}^{-1}$ with a mean value of $100 \mathrm{Mm}^{-1}$ in the lowest $3 \mathrm{~km}$ a.g.1.. Mean extinction-to-backscatter ratios of 53-55 sr $( \pm 7-13 \mathrm{sr})$ were obtained at 355,532 and $1064 \mathrm{~nm}$. A significant wavelength dependence of the lidar ratio was not observed close to the source region of atmospheric desert dust.

\section{Acknowledgments}

We are grateful to the Moroccan Ministry for Foreign Affairs and the Ministry of the Interior for the permission to carry out the SAMUM field campaign in Morocco. We would like to extend our gratefulness to the Moroccan Airport Authority and, in particular, to respectable Monsieur Mohammed El Mardi, commander of Ouarzazate airport, for their extraordinary support of the participants of SAMUM. Our boundless thanks go to our multilingual Moroccan friend, Mr. Nabil Bousselham. Without his tireless efforts in negotiating with the Moroccan Government and local authorities, this field campaign would have hardly become reality. His immeasurable talent of organizing whatever we needed during our SAMUM campaign kept us in an inexhaustible astonishment.We would like to express our thanks to the AERONET team for instrument calibration and for data analysis. The SAMUM research group is funded by the Deutsche Forschungsgemeinschaft (DFG) under grant number FOR 539. We furthermore thank the Johannes Gutenberg University Mainz for its financial support through the research funds of the University of Mainz. 


\section{References}

Ackermann, J., Völger, P. and Wiegner, M. 1999. Significance of multiple scattering from tropospheric aerosols for ground-based backscatter lidar measurements. Appl. Opt. 38, 5195-5201.

Althausen, D., Müller, D., Ansmann, A., Wandinger, U., Hube, H. and co-authors. 2000. Scanning 6-wavelength 11-channel aerosol lidar. $J$. Atmos. Ocean. Technol. 17, 1469-1482.

Amiridis, V., Balis, D. S., Kazadzis, S., Bais, A. and Giannakaki, E. 2005. Four-year aerosol observation with a Raman lidar at Thessaloniki, Greece, in the framework of the European Aerosol Research Lidar Network (EARLINET). J. Geophys. Res. 110, doi:10.1029/2005JD006190.

Ansmann, A. 2006. Ground-truth aerosol lidar observations: can the Klett solutions obtained from ground and space be equal for the same aerosol case?. Appl. Opt. 45, 3367-3371.

Ansmann, A. and Müller, D. 2005. Lidar and atmospheric aerosol particles. In: LIDAR - Range-resolved Optical Remote Sensing of the Atmosphere (ed. C., Weitkamp). Springer, New York, 105-141.

Ansmann, A., Wandinger, U., Wiedensohler, A. and Leiterer, U. 2002a. Lindenberg aerosol characterization experiment 1998 (LACE 98): overview. J. Geophys. Res. 107, doi:10.1029/2000JD000233.

Ansmann, A., Wagner, F., Müller, D., Althausen, D., Herber, A. and coauthors. 2002b. European pollution outbreaks during ACE 2: optical particle properties inferred from multiwavelength lidar and star-Sun photometry. J. Geophys. Res. 107, doi:10.1029/2001JD001109.

Ansmann, A., Bösenberg, J., Chaikovsky, A., Comerón, A., Eckhardt, S. and co-authors. 2003. Long-range transport of Saharan dust to northern Europe: the 11-16 October 2001 outbreak observed with EARLINET. J. Geophys. Res. 108, doi:10.1029/2003JD003757.

Ansmann, A., Tesche, M., Althausen, D., Müller, D., Freudenthaler, V. and co-authors. 2008. Influence of Saharan dust on cloud glaciation in southern Morocco during SAMUM. J. Geophys. Res. 113, doi:10.1029/2007JD008785.

Ansmann, A., Tesche, M., Knippertz, P., Bierwirth, E., Althausen, D. and co-authors. 2008. Vertical profiling of convective dust plumes in southern Morocco during SAMUM. Tellus 61B, doi:10.1111/j.16000889.2008.00384.x.

Arshinov, Y, Bobrovnikov, S., Serikov, I., Ansmann, A., Wandinger, U., and co-authors. 2005. Daytime operation of a pure rotational Raman lidar by the use of a Fabry-Perot interferometer. Appl. Opt. 44, 35933603.

Ångström, A. 1961. Techniques for determining the turbidity of the atmosphere. Tellus 13, 214-223.

Ångström, A. 1964. The parameters of atmospheric turbidity. Tellus 16, 64-75.

Balis, D. S., Amiridis, V., Nickovic, S., Papayannis, A. and Zerefos, C. 2004. Optical properties of Saharan dust layers as detected by a Raman lidar at Thessaloniki, Greece. Geophys. Res. Lett. 31, doi:10.1029/2004GL019881.

Barnaba, F. and Gobbi, G. P. 2001. Lidar estimation of tropospheric aerosol extinction, surface area and volume: maritime and desert-dust cases. J. Geophys. Res. 106, 3005-3018.

Berthier, S., Chazette, P., Couvert, P., Pelon, J., Dulac, F., and co-authors. 2006. Desert dust aerosol columnar properties over ocean and continental Africa from lidar in-space technology experiment (LITE) and Meteosat synergy. J. Geophys. Res. 111, doi:10.1029/2005JD006999.
Bierwirth, E., Wendisch, M., Ehrlich, A., Heese, B., Tesche, M. and coauthor 2008. Spectral surface albedo over Morocco and its impact on the radiative forcing of Saharan dust. Tellus 61B, doi:10.1111/j.16000889.2008.00395.x.

Chen, W. N., Tsai, F. J., Chou, C. C. K., Chang, S. Y., Chen, Y. W., and coauthors. 2007. Optical properties of Asian dust in the free atmosphere measured by Raman lidar at Taipei, Taiwan. Atmos. Environ. 41, 7698-7714.

De Tomasi, F., Blanco, A. and Perrone, M. R. 2003. Raman lidar monitoring of extinction and backscattering of African dust layers and dust characterization. Appl. Opt 42, 1699-1709.

Dinter, T., von Hoyningen-Huene, W., Burrows, J. P., Kokhanovsky, A., Bierwirth, E. and co-authors. 2008. Retrieval of aerosol optical thickness for desert conditions using MERIS observations during the SAMUM campaign. Tellus 61B, doi:10.1111/j.1600-0889.2008.00391.x.

Dubovik, O., Holben, B. N., Lapyonok, T., Sinyuk, A., Mishchenko, M. I., and co-authors. 2002. Non-spherical aerosol retrieval method employing light scattering by spheroids. Geophys. Res. Lett. 29, doi:10.1029/2001GL014506.

Dubovik, O., Sinyuk, A., Lapyonok, T., Holben, B. N., Mishchenko, M. I., and co-authors. 2006. Application of spheroid models to account for aerosol particle nonsphericity in remote sensing of desert dust. $J$. Geophys. Res. 111, doi:10.1029/2005JD006619.

Eck, T. F., Holben, B. N., Reid, J. S., Dubovik, O., Smirnov, A., and co-authors. 1999. Wavelength dependence of the optical depth of biomass burning, urban, and desert dust aerosols. J. Geophys. Res. 104, 31 333-31349.

Esselborn, M., Wirth, M., Fix, A., Tesche, M. and Ehret, G. 2008. Airborne high spectral resolution lidar for measuring aerosol extinction and backscatter coefficients. Appl. Opt. 47, 346-358.

Esselborn, M., Wirth, M., Fix, A., Weinzierl, B., Rasp, K. and co-authors. 2008. Spatial distribution and optical properties of Saharan dust observed by airborne high spectral resolution lidar during SAMUM 2006. Tellus 61B, doi:10.1111/j.1600-0889.2008.00394.x.

Fernald, F. G. 1984. Analysis of atmospheric lidar observations: some comments. Appl. Opt. 23, 652-653.

Franke, K., Ansmann, A., Müller, D., Althausen, D., Venkataraman, C. and co-authors. 2003. Optical properties of the Indo-Asian haze layer over the tropical Indian Ocean. J. Geophys. Res. 108, doi:10.1029/2002JD002473.

Freudenthaler, V., Esselborn, M., Wiegner, M., Heese, B., Tesche, M. and co-authors. 2008. Depolarization-ratio profiling at several wavelengths in pure Saharan dust during SAMUM 2006. Tellus 61B, doi:10.1111/j.1600-0889.2008.00396.x.

Heese, B., Althausen, D., Dinter, T., Esselborn, M., Müller, T., and co-authors. 2008. Vertically resolved dust optical properties during SAMUM. Tinfou compared to Ouarzazate Tellus 61B, doi:10.1111/j.1600-0889.2008.00404.x.

Heese, B., Freudenthaler, V., Seefeldner, M. and Wiegner, M. 2002. POLIS: a new portable system for ground-based and airborne measurements of aerosols and clouds. In: Lidar Remote Sensing in Atmospheric and Earth Sciences, (eds. L. R. Bissonnette, G. Roy and G. Vallee), Defence Research and Development, Canada-Valcartier, Val-Belair, QU, Canada . 71-74.

Heinold, B., Tegen, I., Esselborn, M., Kandler, K., Knippertz, P. and coauthors. 2008. Regional Saharan dust modelling during the SAMUM 2006 campaign. Tellus 61B, doi: 10.1111/j.1600-0889.2008.00387.x. 
Heintzenberg, J. 2008. The SAMUM-1 experiment over Southern Morocco: overview and introduction. Tellus 61B, doi: 10.1111/j.16000889.2008.00403.x.

Holben, B. N., Eck, T. F., Slutsker, I., Tanré, D., Buis, J. P., and coauthors. 1998. AERONET — a federated instrument network and data archive for aerosol characterization. Remote Sens. Environ. 66, 1-16.

Kahn, R. A., Petzold, A., Wendisch, M., Bierwirth, E., Dinter, T. and co-authors. 2008. Desert dust air mass mapping in the western Sahara, using particle properties derived from space-based multi-angle imaging. Tellus 61B, doi:10.1111/j.1600-0889.2008.00398.x.

Kandler, K., Schütz, L., Deutscher, C., Hofmann, H., Jäckel, S. and co-authors. 2008. Size distributions, mass concentration, chemical and mineralogical composition, and derived optical parameters of the boundary layer aerosol at Tinfou, Morocco, during SAMUM 2006. Tellus 61B, doi:10.1111/j.1600-0889.2008.00385.x.

Kaufman, Y., Tanré, D., Léon, J.-F. and Pelon, J. 2003. Retrievals of profiles of fine and coarse aerosols using lidar and radiometric space measurements. IEEE Trans. Geosci. Remote Sens. 41, 1743-1754.

Knippertz, P., Ansmann, A., Althausen, D., Müller, D., Tesche, M. and co-authors. 2008. Dust mobilization and transport in the northern Sahara during SAMUM 2006 - A meteorological overview. Tellus 61B, doi:10.1111/j.1600-0889.2008.00380.x.

Léon, J.-F., Tanré, D., Pelon, J., Kaufman, Y. J., Haywood, J. M., and co-authors. 2003. Profiling of a Saharan dust outbreak based on a synergy between active and passive remote sensing. J. Geophys. Res. 108, doi:10.1029/2002JD002774.

Liu, Z., Sugimoto, N. and Murayama, T. 2002. Extinction-to-backscatter ratio of Asian dust observed with high-spectral-resolution lidar and Raman lidar. Appl. Opt. 41, 2760-2767.

Liu, Z., Omar, A., Vaughan, M., Hair, J., Kittaka, C., and co-authors. 2008. CALIPSO lidar observations of the optical properties of saharan dust: A case study of long-range transport. J. Geophys. Res. 113, doi:10.1029/2007JD008878.

Mattis, I., Ansmann, A., Müller, D., Wandinger, U. and Althausen, D. 2002a. Errors in backscatter profiles caused by a depolarizationdependent receiver transmission. In: Lidar Remote Sensing in Atmospheric and Earth Sciences (eds. L. R., Bissonnette, G., Roy and G., Vallee). Defence Research and Development, Canada-Valcartier, Val-Belair, QU, Canada. 121-124.

Mattis, I., Ansmann, A., Althausen, D., Jaenisch, V., Wandinger, U., and co-authors. 2002b. Relative-humidity profiling in the troposphere with a Raman lidar. Appl. Opt. 41, 6451-6462.

Mattis, I., Ansmann, A., Müller, D., Wandinger, U. and Althausen, D. 2002c. Dual-wavelength Raman lidar observations of the extinctionto-backscatter ratio of Saharan dust. Geophys. Res. Lett. 29, doi:10.1029/2002GL014721.

Mattis, I., Ansmann, A., Müller, D., Wandinger, U. and Althausen, D. 2004. Multiyear aerosol observations with dual-wavelength Raman lidar in the framework of EARLINET. J. Geophys. Res. 109, doi:10.1029/2004JD004600.

Mishchenko, M. I., Travis, L. D., Kahn, R. A. and West, R. A. 1997. Modeling phase functions for dustlike tropospheric aerosols using a shape mixture of randomly oriented polydisperse spheroids. J. Geophys. Res. 102, 16831-16847.

Mona, L., Amodeo, A., Pandolfi, M. and Pappalardo, G. 2006. Saharan dust intrusions in the Mediterranean area: Three years of Raman lidar measurements. J. Geophys. Res. 111, doi:10.1029/2005JD006569.
Murayama, T., Masonis, S. J., Redemann, J., Anderson, T. L., Schmid, B., and co-authors. 2003. An intercomparison of lidar-derived aerosol optical properties with airborne measurements near Tokyo during ACE-Asia. J. Geophys. Res. 108, doi:10.1029/2002JD003259.

Murayama, T., Müller, D., Wada, K., Shimizu, A., Sekiguchi, M., and co-authors. 2004. Characterization of Asian dust and Siberian smoke with multiwavelength Raman lidar over Tokyo, Japan in spring 2003. Geophys. Res. Lett. 31, doi:10.1029/2004GL021105.

Müller, D., Heinhold, B., Tesche, M., Tegan, I., Althausen, D. and coauthors. 2008. Observations of the 14-22-May Long-range dust transport event during SAMUM 2006: Validation of results from dust transport Modelling, Tellus 61B, doi: 10.1111/j.1600-0889.2008.00400.x.

Müller, D., Mattis, I., Wandinger, U., Ansmann, A., Althausen, D., and co-authors. 2003. Saharan dust over a central European EARLINETAERONET site: combined observations with Raman lidar and Sun photometer. J. Geophys. Res. 108, doi:10.1029/2002JD002918.

Müller, D., Ansmann, A., Mattis, I., Tesche, M., Wandinger, U., and co-authors. 2007. Aerosol-type-dependent lidar ratios observed with Raman lidar. J. Geophys. Res. 112, doi:10.1029/2006JD008292.

Noh, Y. M., Kim, Y. J., Choi, B. C. and Murayama, T. 2007. Aerosol lidar ratio characteristics measured by a multi-wavelength Raman lidar system at Anmyeon Island, Korea. Atmos. Res. 86, 7687.

Otto, S., Bierwirth, E., Weinzierl, B., Kandler, K., Esselborn, M. and coauthors. 2008. Solar radiative effects of a Saharan dust plume observed during SAMUM assuming spheroidal model particles. Tellus 61B, doi:10.1111/j.1600-0889.2008.00389.x.

Papayannis, A., Amiridis, V., Mona, L., Tsaknakis, G., Balis, D., and co-authors. 2008. Systematic lidar observations of Saharan dust over Europe in the frame of EARLINET (2000-2002). J. Geophys. Res. 113, doi: $10.1029 / 2007$ JD009028.

Petzold, A., Rasp, K., Weinzierl, B., Esselborn, M., Hamburger, T. and co-authors. 2008. Saharan dust absorption and refractive index from aircraft-based observations during SAMUM 2006. Tellus 61B, doi:10.1111/j.1600-0889.2008.00383.x.

Russel, P. B. and Heintzenberg, J. 2000. An overview of the ACE2 clear sky column closure experiment (CLEARCOLUMN). Tellus 52B, 463-483.

Sakai, T., Shibata, T., Iwasaka, Y., Nagai, T., Nakazato, M. and coauthors. 2002. Case study of Raman lidar measurements of Asian dust events in 2000 and 2001 at Nagoya and Tsukuba, Japan. Atmos. Environ. 36, 5479-5489.

Tanré, D., Haywood, J., Pelon, J., Léon, J.-F., Chatenet, B., and coauthors. 2003. Measurements and modeling of the Saharan dust radiative impact: overview of the Saharan Dust Experiment (SHADE). J. Geophys. Res. 108, doi:10.1029/2002JD003273.

Tesche, M., Ansmann, A., Müller, D., Althausen, D., Engelmann, R., and co-authors. 2007. Particle backscatter, extinction, and lidar ratio profiling with Raman lidar in South and North China. Appl. Opt. 46, 6302-6308.

Toledano, C., Wiegner, M., Garhammer, M., Seefeldner, M., Gasteiger, J. and co-authors. 2008. Spectral aerosol optical depth characterization of desert dust during SAMUM 2006. Tellus 61B, doi:10.1111/j.1600-0889.2008.00382.x.

Wandinger, U. 1998. Multiple-scattering influence on extinction- and backscatter-coefficient measurements with Raman and high-spectralresolution lidars. Appl. Opt. 37, 417-427. 
Wandinger, U. and Ansmann, A. 2002. Experimental determination of the lidar overlap profile with Raman lidar. Appl. Opt. 41, 511514.

Wandinger, U., Müller, D., Böckmann, C., Althausen, D., Matthias, V., and co-authors. 2002. Optical and microphysical characterization of biomass-burning and industrial-pollution aerosols from multiwavelength lidar and aircraft measurements. J. Geophys. Res. 107, doi:10.1029/2000JD000202.

Weinzierl, B., Petzold, A., Esselborn, M., Wirth, M., Rasp, K. and coauthors. 2008. Airborne measurements of dust layer properties, particle size distribution and mixing state of Saharan dust during SAMUM 2006. Tellus 61B, doi:10.1111/j.1600-0889.2008.00392.x.

Wernli, H. and Davies, H. C. 1997. A Lagrangian-based analysis of extratropical cyclones, I: the method and some applications. Q. J. R. Meteorol. Soc., 123, 467-489.

Wiegner, M., Quenzel, H., Rabus, D., Völker, W., Völger, P., and co- authors. 1995. The mobile three-wavelength backscatter lidar of the Meteorological Institute of the University Munich. Lidar Atmos. Sens., Proc. SPIE Int. Soc. Opt. Eng. 2505, 2-10.

Wiegner, M., Gasteiger, J., Kandler, K., Weinzierl, B., Rasp, K. and co-authors. 2008. Numerical simulations of optical properties of Saharan dust aerosols with emphasis on lidar applications. Tellus 61B, doi:10.1111/j.1600-0889.2008.00381.x.

Winker, D. M., Hunt, W. H. and McGill, M. J. 2007. Initial performance assessment of CALIOP. Geophys. Res. Lett. 34, doi:10.1029/2007GL030135.

Young, S. A., Winker, D. M., Vaughan, M. A., Powell, K. A. and Kuehn, R. A. 2006. Treatment of multiple-scattering effects in extinction retrievals in complex atmospheric scenes probed by CALIPSO. In: Reviewed and Revised Papers Presented at the 23rd International Laser Radar Conference 24-28 July 2006 (eds. C. Nagasawa and N. Sugimoto). Nara, Japan ,.ISBN4-9902916-0-3. 